\title{
BACE2 distribution in major brain cell types and identification of novel substrates
}

\author{
Iryna Voytyuk $k^{1,2}$, Stephan A Mueller ${ }^{3,4}$, Julia Herber ${ }^{3,4}$, An Snellinx ${ }^{1,2}$, Dieder Moechars ${ }^{5}$, Geert van Loo $0^{6,7}$ (D, \\ Stefan F Lichtenthaler ${ }^{3,4,8,9}$, Bart De Strooper ${ }^{1,2,9,10}$ (D)
}

\begin{abstract}
$\beta$-Site APP-cleaving enzyme 1 (BACE1) inhibition is considered one of the most promising therapeutic strategies for Alzheimer's disease, but current BACE1 inhibitors also block BACE2. As the localization and function of BACE2 in the brain remain unknown, it is difficult to predict whether relevant side effects can be caused by off-target inhibition of BACE2 and whether it is important to generate BACE1-specific inhibitors. Here, we show that BACE2 is expressed in discrete subsets of neurons and glia throughout the adult mouse brain. We uncover four new substrates processed by BACE2 in cultured glia: vascular cell adhesion molecule 1, delta and notch-like epidermal growth factor-related receptor, fibroblast growth factor receptor 1 , and plexin domain containing 2 . Although these substrates were not prominently cleaved by BACE2 in healthy adult mice, proinflammatory TNF induced a drastic increase in BACE2-mediated shedding of vascular cell adhesion molecule 1 in CSF. Thus, although under steady-state conditions the effect of BACE2 cross-inhibition by BACE1-directed inhibitors is rather subtle, it is important to consider that side effects might become apparent under physiopathological conditions that induce TNF expression.
\end{abstract}

DOI 10.26508/lsa.201800026 | Received 29 January 2018 | Revised 29 January 2018 | Accepted 1 February 2018 | Published online 15 February 2018

\section{Introduction}

Currently, $\beta$-site APP-cleaving enzyme 1 (BACE1) is considered the major therapeutic target for Alzheimer's disease (AD) (Cole \& Vassar, 2007; Vassar et al, 2014; Yan \& Vassar, 2014; Barão et al, 2016). Together with $\gamma$-secretase, it generates amyloid- $\beta$, a short hydrophobic peptide that aggregates extracellularly into amyloid plaques in the brain of AD patients (De Strooper et al, 1998; Vassar et al, 1999; Hardy \& Selkoe, 2002). Although the genetic evidence strongly supports the targeting of $y$-secretases (Szaruga et al, 2017;
Voytyuk et al, 2017) to lower amyloid- $\beta$ generation in the brain of patients, the severe side effects observed in phase 3 clinical trials have brought $y$-secretase research almost to an end (Doody et al, 2013; De Strooper, 2014). Alternatively, BACE1 inhibition strategies have now taken center stage in the fight against the disease, and several potent, brain-penetrant compounds have entered phase 3 clinical trials (reviewed in Vassar et al, 2014; Barão et al, 2016). The development and evaluation proceed cautiously as BACE1 can cleave numerous other substrates besides amyloid precursor protein (APP) (Kuhn et al, 2012; Zhou et al, 2012; Dislich et al, 2015). These substrates have been linked to synaptic plasticity (Wiera \& Mozrzymas, 2015; Hu et al, 2016; Munro et al, 2016; Pigoni et al, 2016), myelination (Hu et al, 2006; Willem et al, 2006; Fleck et al, 2013; Van Bebber et al, 2013), and axonal outgrowth (Wright et al, 2007; Hitt et al, 2012; Barão et al, 2015) among the most studied functions.

In addition, all available BACE1 inhibitors that are currently tested in the clinic cross-inhibit BACE2, the close homologue of BACE1 (Bennett et al, 2000; Farzan et al, 2000). Most of the inhibitors are equipotent (Neumann et al, 2015; Cebers et al, 2016a), with MK8931 showing even higher selectivity for BACE2 (Kennedy et al, 2016). Similar to BACE1, BACE2 is a type I transmembrane protein that belongs to the peptidase A1 family (also called the pepsin family) of aspartyl proteases. Unlike BACE1, which is highly expressed in the brain, BACE2 is more prominently found in peripheral tissues, namely, the colon, kidney, and pancreas (Bennett et al, 2000). In pancreatic $\beta$ cells, for example, BACE2 cleaves the pro-proliferative plasma membrane protein TMEM27, thereby impacting $\beta$ cell mass and function (Esterházy et al, 2011). Furthermore, BACE2 suppression promotes $\beta$ cell survival through another potential substrate, islet amyloid polypeptide, whose overexpression induces glucose tolerance defects (Rulifson et al, 2016; Alcarraz-Vizán et al, 2017). In this regard, inhibition of BACE2 has even been proposed for the treatment of diabetes (Esterházy et al, 2011; Stützer et al, 2013). BACE2 also processes the pigment cell-specific melanocyte protein involved in melanosome formation in pigment cells (Rochin et al,

\footnotetext{
${ }^{1}$ Department of Neurosciences, Katholieke Universiteit Leuven, Leuven, Belgium ${ }^{2}$ Centre for Brain and Disease Research, Flanders Institute for Biotechnology (VIB), Leuven, Belgium ${ }^{3}$ German Center for Neurodegenerative Diseases (DZNE), Munich, Germany ${ }^{4}$ Neuroproteomics, School of Medicine, Klinikum Rechts der Isar, Technische Universität München, Munich, Germany ${ }^{5}$ Discovery Neuroscience, Janssen Research and Development, Division of Janssen Pharmaceutica NV, Beerse, Belgium ${ }^{6}$ Center for Inflammation Research, VIB, Gent, Belgium ${ }^{7}$ Department of Biomedical Molecular Biology, Gent University, Gent, Belgium ${ }^{8}$ Institute for Advanced Study, Technische Universität München, Munich, Germany ${ }^{9}$ Munich Cluster for Systems Neurology, Munich, Germany ${ }^{10}$ Dementia Research Institute, Institute of Neurology, University College London, London, UK
}

Correspondence: Bart.DeStrooper@kuleuven.vib.be 
2013). As a result, genetic knockout (KO) or pharmacological inhibition of BACE2 results in depigmentation, the most obvious phenotype of mouse Bace $\mathrm{KO}$ models and the most consistent side effect seen in preclinical studies of BACE1/2 inhibition (Dominguez et al, 2005; Shimshek et al, 2016; Cebers et al, 2016b; Voytyuk et al, 2017).

Thus, although some research has already indicated potential problems with peripheral inhibition of BACE2, surprisingly little is known about the function of BACE2 in the brain, the main target organ for BACE1 inhibitors. Using a sensitive and very specific in situ hybridization technique, we show here that Bace2 mRNA is expressed in subsets of neurons, oligodendrocytes, and astrocytelike cells lining the lateral ventricles in the mouse brain. Although all major cell types express Bace2, the levels vary considerably within the cell types in different regions of the brain. Using liquid chromatography coupled with tandem mass spectrometry (LC-MS/ MS) to analyze the conditioned medium of cultured mouse glia, we uncover and validate four previously unknown substrates of Bace2: vascular cell adhesion molecule 1 (VCAM1), delta and notch-like epidermal growth factor-related receptor (DNER), fibroblast growth factor receptor 1 (FGFR1), and plexin domain containing 2 (PLXDC2). We find that under constitutive, nonstimulated conditions, the extent of substrate cleavage by BACE2 is low. However, we demonstrate that BACE2 cleavage of the new substrate VCAM1 gets strongly up-regulated under inflammatory conditions in vitro and in vivo. Neuroinflammation is one of the hallmarks of $A D$, and several inflammatory cytokines, in particular TNF and IL-1 $\beta$, are known to be up-regulated in both the periphery and the brain of $A D$ patients (Akiyama et al, 2000; Sastre et al, 2006; Wang et al, 2015; Lai et al, 2017). Our findings indicate that BACE2 may be an important secretase under inflammatory conditions in the brain.

\section{Results}

\section{Bace2 expression in the mouse brain}

To characterize Bace2 expression in the brain and compare it with that of Bace1, we used the RNAscope Fluorescent Multiplex Assay (ACD Bio). This in situ hybridization technique uses 20 probe pairs and four amplification steps to allow quantitative detection of a single RNA molecule with excellent sensitivity and specificity.
RNAscope in situ hybridization data show that Bace2 is less widely expressed in the mouse brain than Bace1. Characterization of the expression pattern and relative abundance in different brain areas and cell types is summarized in Table 1 and examples of expression patterns are shown in Fig 1. Synaptophysin (Syp), glutamate aspartate transporter (Glast), and myelin basic protein (Mbp) were used as specific markers for neurons, astrocytes, and oligodendrocytes, respectively, demonstrating that Bace2 expression can be detected in all three cell types (Fig $1 \mathrm{~A}-\mathrm{C}$ ). It is interesting that Bace 2 expression in these cells varies across different brain regions. To evaluate the level of expression of our secretases of interest, we compared them with markers and reference genes used by RNAscope with known expression levels (Fig S1) (Zhang et al, 2014). Highest neuronal expression is found in the mouse ventral hippocampus at $4 \mathrm{mo}$ (Fig 1D). The lining of the lateral ventricle is the only brain area showing Bace2 expression in astrocytes (Fig 1E), whereas in oligodendrocytes, especially in young animals, Bace 2 is found throughout the fiber tracts (Fig 1F). Although in most cases Bace1 is expressed in Bace2-positive cells (Fig 1G), the reverse is not true, as Bace1 is much more widely expressed in the brain. For instance, Bace1 is abundant in neuronal-rich areas, such as the hippocampus, thalamus, and cortex, showing much higher expression than Bace2. Many neurons, such as Purkinje cells, express only Bace1 (Fig 1I), and there are whole neuron-rich areas, such as the dorsal hippocampus, with high Bace1 expression, but virtually devoid of Bace2 (Fig 1J). Some oligodendrocytes in the fiber tracts of the striatum, cerebellum, and corpus callosum express both secretases, with Bace1 being more abundant (Fig $1 \mathrm{H})$. Interestingly, expression of both Bace1 and Bace2 in oligodendrocytes is highest in young postnatal day $(P) 16$ animals, at the age of myelination onset. Few astrocytes throughout the brain focally express Bace1, whereas Bace2 is only expressed at the astrocytes lining the lateral ventricle (Fig $1 \mathrm{~K}$ ).

\section{Identification of Bace2 substrate candidates}

As Bace2 is clearly expressed in various brain cell types, we set out to uncover its substrates. Following the approach of a previous study of BACE1 substrates in CSF (Dislich et al, 2015), we examined mouse CSF with mass spectrometry, comparing the CSF of double $\mathrm{KO}$ (dKO) mice with that of Bace ${ }^{-/-}$mice (Fig S2 and Table S1). Overall, 579 proteins were quantified in at least three replicates of

Table 1. Summary of BACE2 and BACE1 expression in the mouse brain.

\begin{tabular}{lllll} 
Brain area & $\begin{array}{l}\text { BACE2 } \\
\text { expression }\end{array}$ & $\begin{array}{l}\text { BACE2 expressing cell } \\
\text { types }\end{array}$ & $\begin{array}{l}\text { BACE1 } \\
\text { expression }\end{array}$ & BACE1 expressing cell types \\
\hline Hippocampus (dorsal) & - & Not found & ${ }^{++}$ & Neurons \\
\hline Hippocampus (ventral CA3 and subiculum) & ++ & Neurons & Neurons \\
\hline $\begin{array}{l}\text { Cortex (highest in motor and somatosensory layers } 4 \\
\text { and 5) }\end{array}$ & + & Neurons & ++ & Neurons, occasional astrocytes \\
\hline Thalamus & + & Neurons & ++ & Neurons, occasional astrocytes \\
\hline Cerebellum & + & Oligodendrocytes & ++ & Neurons, oligodendrocytes \\
\hline Striatum & + & Oligodendrocytes & ++ & Oligodendrocytes \\
\hline Fiber tracts &,+++ at P16 & Oligodendrocytes &,++++ at P16 & Oligodendrocytes, astrocytes \\
\hline Lateral ventricle lining & + & Astrocytes & - & Not found \\
\hline
\end{tabular}


A

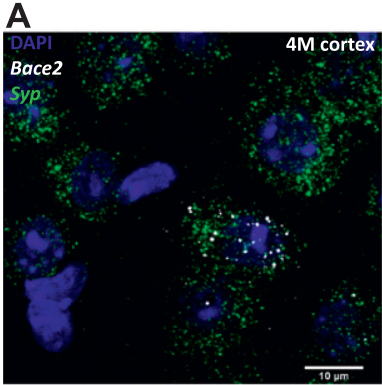

D

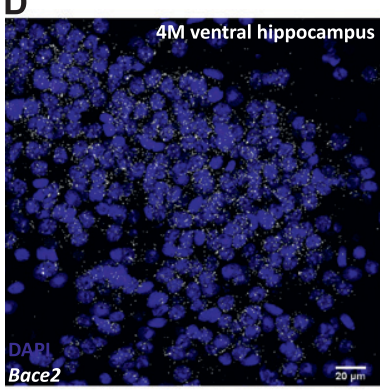

G

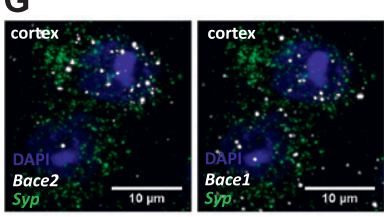

$\mathrm{J}$
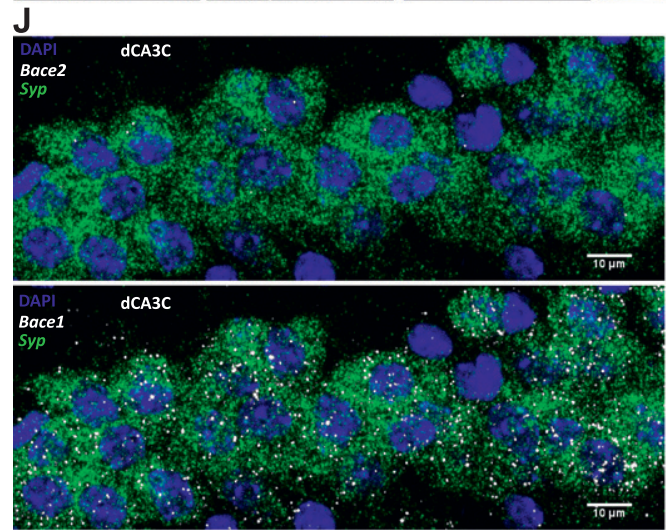

B

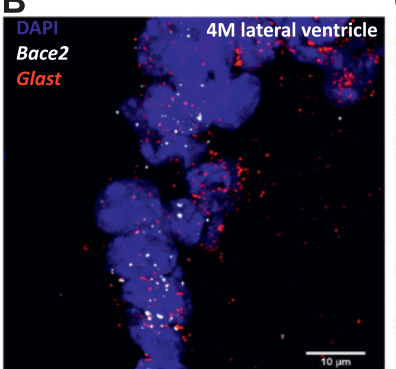

C

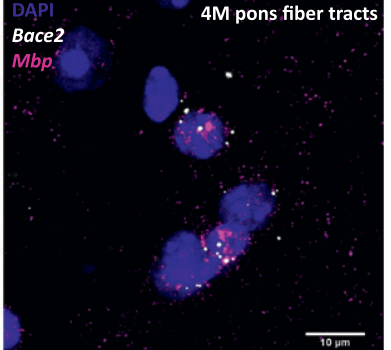

E

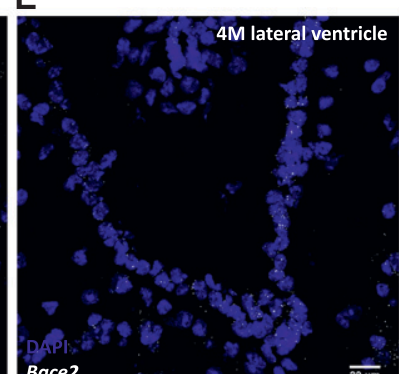

$\mathrm{H}$

$\mathbf{F}$

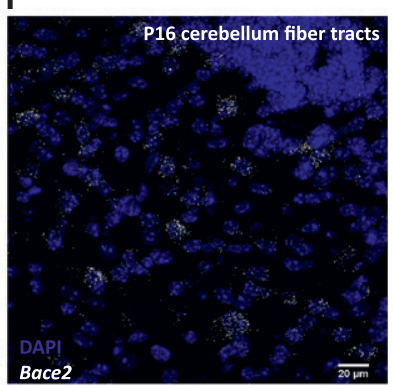

I
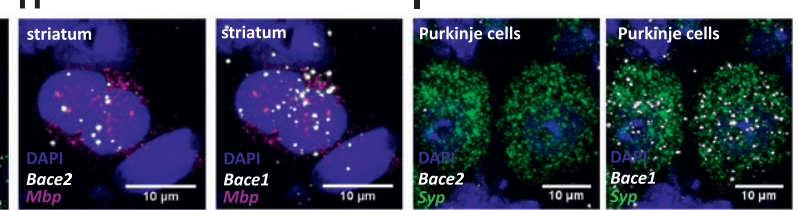

K

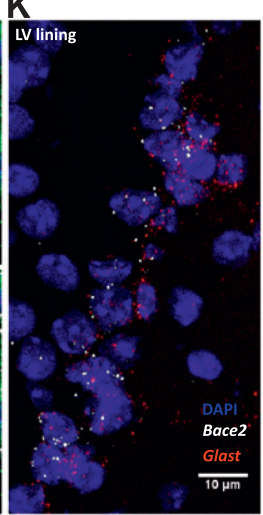

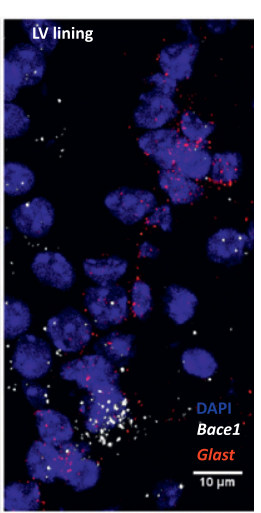

Figure 1. Bace2 mRNA expression in neurons, astrocytes, and oligodendrocytes.

Examples of Bace2 mRNA expression in neurons (A), astrocytes (B), and oligodendrocytes (C) as identified by co-localized cell type-specific markers Syp, Glast, and $M b p$, respectively. Brain areas with highest neuronal (D), astrocyte (E), and oligodendrocyte (F) expression of Bace2. Neurons (G), as well as oligodendrocytes $(H)$, expressing Bace2 also express Bace1. Purkinje cells express only Bace1 (I); similarly, dorsal hippocampus shows high Bace1 expression, but is virtually devoid of Bace2 (J). Few astrocytes throughout the brain focally express Bace1, whereas Bace2 is only expressed by astrocytes lining the lateral ventricle (K). Representative images from two adult (4 mo) and two young (P16-20) male WT mice. Syp, neuronal marker; Glast, astrocytic marker; and $\mathrm{Mbp}$, oligodendrocyte marker. both, Bace $^{-/-}$and dKO mouse CSF. A subset of 60 proteins showed a log2-transformed ratio of at least \pm 0.5 ( $>1.41$-fold or $<0.71$-fold) with $P$-value $<0.05$ (Table S1). The analysis demonstrated pronounced increases and decreases in cytosolic proteins such as IGAC, SERPINA3M, IGHG1, IGG2AC and SCG5, LY86, OGN, and C2 (Fig S2). Among the increased proteins, we found proteins of the immunoglobulin family and a member of the serpin family of serine protease inhibitors, whose functions are not clearly understood (Silverman et al, 2001). The decreased proteins are a neuroendocrine member of the secretogranin family, a player in the innate immune response, small leucine-rich proteoglycan, and members of the complement system (Taupenot et al, 2003; Deckx et al, 2016; Hasan et al, 2017). However, as none of these proteins harbors a transmembrane domain, they are unlikely to be direct BACE2 substrates, and the observed changes are likely due to the indirect effects of BACE2 absence (in the background of Bace ${ }^{-/-}$). Singlespan transmembrane proteins LRRN1, PLXDC2, CNTN2, and PTPRN2 that were previously identified as BACE1 substrates are given in bold in Fig S2 (Kuhn et al, 2012; Zhou et al, 2012; Dislich et al, 2015); they are likely direct BACE2 substrates as well, but are only partially cleaved by BACE2 (31-51\% decreases reflect BACE2 contribution on top of BACE1 inhibition). This demonstrates that BACE2 inactivation alters BACE2 substrate levels in the murine CSF proteome.

Proteins in CSF may originate from all brain cell types. As shown in Fig 1, these express highly variable levels of BACE2 (Table 1). Thus, we further examined BACE2 substrate candidates with brain relevance by turning to a primary cell culture, where BACE2 was previously shown to be expressed and active (Dominguez et al, 2005). Glia were cultured in the presence or absence of the unselective inhibitor Compound J (CpJ), which blocks both BACE1 and BACE2. 
A

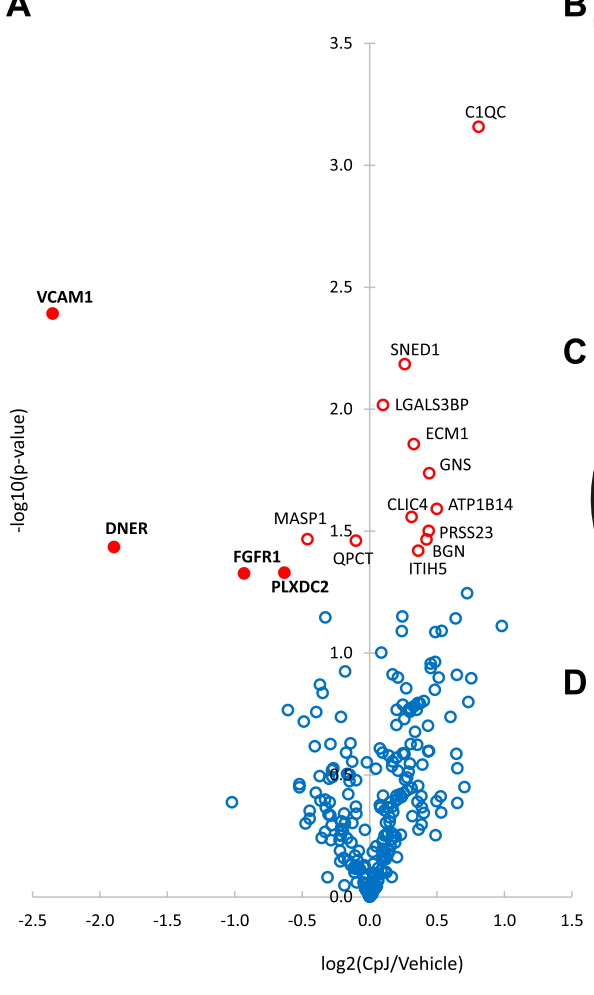

B

C
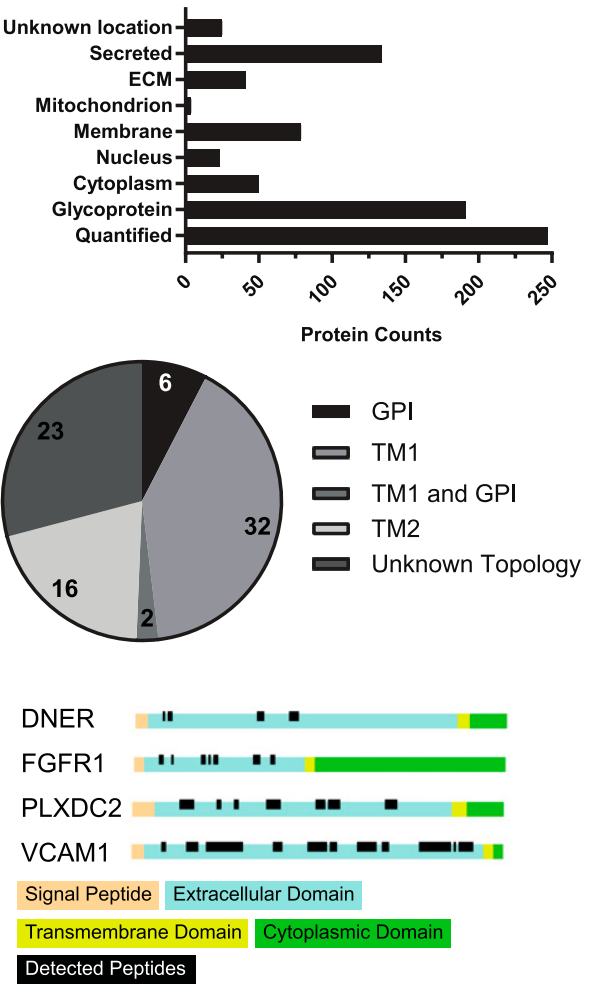

Figure 2. BACE2 secretome in primary glia cultures. (A) Volcano plot of proteomic analysis of conditioned medium from Bace1 ${ }^{-/-}$cultured glia treated with BACE inhibitor $\mathrm{CpJ}$ or vehicle $(\mathrm{n}=3)$. For each relatively quantified protein (representing a dot on the plot), the -log10-transformed $t$ test $P$-value was plotted against the log2-transformed LFQ intensity ratios of $\mathrm{CpJ} /$ vehicle. Proteins with a $t$ test $P$-value $<0.05$ are marked with open red circles, whereas proteins with $P$-value $>0.05$ are shown in blue. Closed red dots labeled with bold letters denote the four substrate candidates that are reduced by more than $30 \%$ in the inhibitor-treated samples. No corrections for multiple hypothesis testing were applied in this discovery experiment. (B) Uniprot subcellular locations of the identified proteins. Glycoproteins were defined according to UniProt Keywords. (C) Topology of membrane proteins according to Uniprot subcellular locations. (D) Uniprot Topology of DNER, FGFR1, PLXDC2, and VCAM1 with mapped identified peptides.
Therefore, we decided to increase the sensitivity of our system by using Bace $^{-/-}$glia to identify proteins selectively shed by BACE2. For this purpose, we used a mass spectrometry-based screening method. Conditioned media of cultures treated with an inhibitor or vehicle only were collected after 48 h. Glycosylated membrane proteins, which constitute nearly $90 \%$ of all single-span membrane proteins, were enriched using the secretome protein enrichment with click sugars method, and proteins were quantified by using LC-MS/MS-based labelfree quantification (LFQ) (Kuhn et al, 2012). Overall, 246 proteins (191 glycoproteins according to UniProt) were relatively quantified in three replicates and subjected to statistical analysis (Fig 2B and C). Six significantly decreased proteins were identified by mass spectrometry analysis in a conditioned medium of primary glia cultures treated with an inhibitor, four of which were decreased by more than 30\%: VCAM1, DNER, FGFR1, and PLXDC2 (Fig 2A and Table S2). All four are, furthermore, type 1 transmembrane proteins, with large extracellular domains with several predicted glycosylation sites (Fig 2D). Only peptides matching the extracellular domains were identified (Fig 2D), which indicates that these proteins were indeed secreted. The shedding of VCAM1 and DNER was very strongly reduced by $80 \%$ and $73 \%$, respectively, suggesting that BACE2 is the main protease cleaving these proteins, with little contribution of other "sheddases" in the glia. FGFR1 and PLXDC2 shedding is, in contrast, only moderately reduced by $48 \%$ and $35 \%$, respectively, suggesting that other proteases are likely contributing to their cleavage.

\section{Validation of BACE2 substrate candidates in cell culture}

The results of the mass spectrometry-based screening were further validated in cell cultures. Specific antibodies for the $\mathrm{N}$-terminal part of VCAM1 and DNER are readily available, allowing their validation as substrates at the endogenous levels of expression. As shown in Fig 3A, shed VCAM1 is detected in a conditioned medium of $\mathrm{Bace}^{-/-}$glia, and this shedding is decreased by $64 \%$ upon inhibition with CpJ (Fig 3A and B). The full-length VCAM1 shows a slight trend to accumulate in the glia cells without reaching statistical significance (Fig 3A and C). Prominent VCAM1 shedding is observed in WT and $\mathrm{Bace}^{-/-}$glia, whereas little shedding is seen in Bace2 $2^{-/-}$ glia (Fig 3D). We next used the Bace inhibitor CpJ in $\mathrm{Bace}^{-/-}, \mathrm{WT}$, and $\mathrm{BaCe}^{-/-}$glia to determine the effect on VCAM1 shedding. Similar to Bace $^{-/-}$glia, shedding of VCAM1 is attenuated in WT glia upon BACE inhibition (Fig 3E), whereas no change is observed in the already low level of shedding in $\mathrm{Bace}^{-/-}$glia (Fig 3F), suggesting that VCAM1 is a selective BACE2 substrate in glia cells and not processed by BACE1.

DNER shedding into the medium is decreased by $75 \%$ upon treating the cells with $\mathrm{CpJ}$ (Fig $3 \mathrm{G}$ and $\mathrm{H}$ ). Full-length DNER does not accumulate in the glia cells (Fig $3 G$ and I). DNER is shed by WT glia, as well as $\mathrm{Bace}^{-/-}$glia, but shedding is prominently decreased in Bace2 $^{-/-}$glia (Fig 3J). CpJ treatment dramatically decreases the shedding of DNER in WT and Bace1 ${ }^{-/-}$glia (Fig $3 G$ and K), but does not further decrease shedding of DNER in $\mathrm{Bace2}^{-/-}$glia cultures (Fig $3 L)$.

Unfortunately, available antibodies for FGFR1 and PLXDC2 crossreact with a variety of proteins when used at the endogenous levels of expression. We, therefore, moved to a COS-1 overexpression system. Shedding of tagged murine PLXDC2 overexpressed in COS-1 cells can be monitored, and commercially available antibody raised against $\mathrm{N}$-terminal FGFR1 detects the high levels of the human 
A

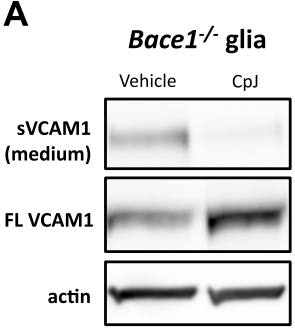

B

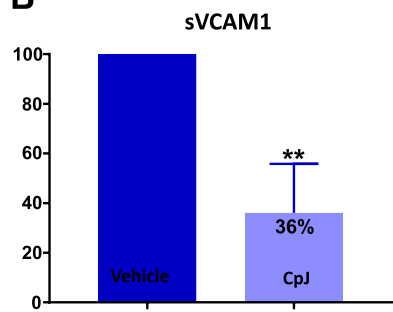

D

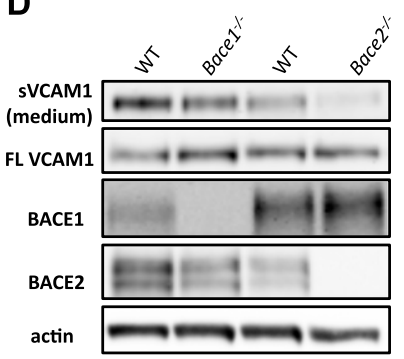

G
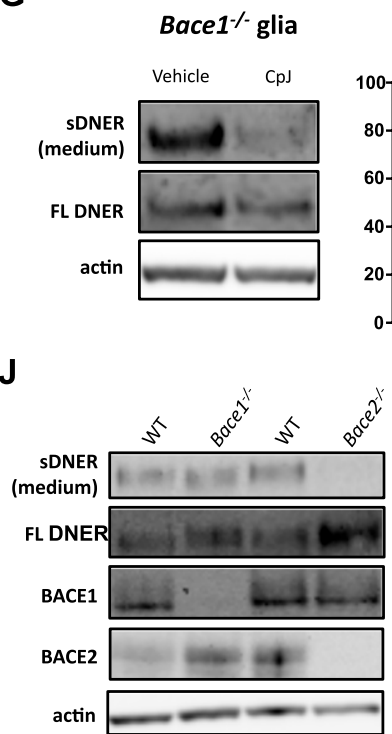

E

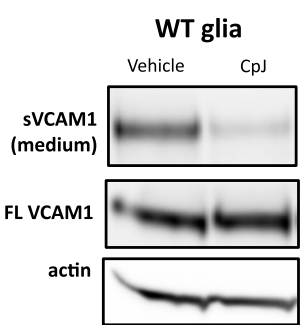

H

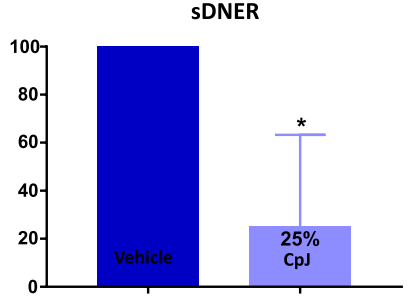

K

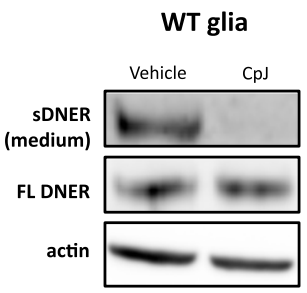

C

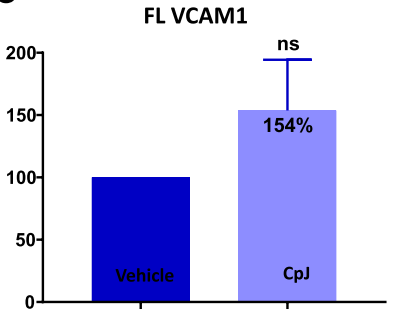

$\mathbf{F}$
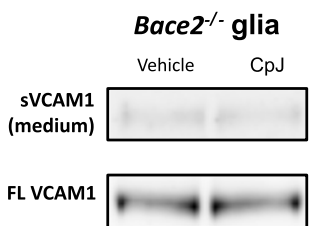

actin

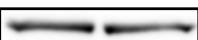

I

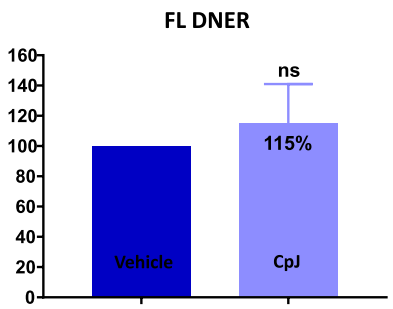

$\mathbf{L}$

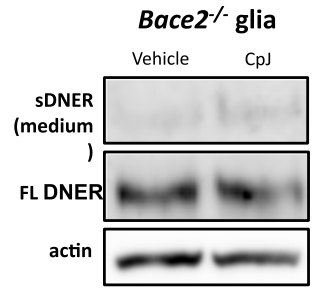

Figure 3. Validation of VCAM1 and DNER as BACE2 substrates in primary mixed glia cultures.

(A) VCAM1 in medium and cell lysates of Bace1 ${ }^{-/-}$glia treated with vehicle or CpJ $(10 \mu M)$ for $24 \mathrm{~h}(n=4)$.

(B) Quantification of VCAM1 shedding into conditioned medium of Bace ${ }^{-/-}$glia treated with vehicle or $\mathrm{CpJ}$ for $24 \mathrm{~h}$ (paired $t$ test, $P=0.01, n=4$ ). (C) Quantification of VCAM1 accumulation in cell lysates of $\mathrm{Bace}^{-/-}$glia treated with vehicle or $\mathrm{CpJ}(10 \mu \mathrm{M})$ for $24 \mathrm{~h}$ (paired $t$ test, $P=0.08, \mathrm{n}=4$ ). (D) VCAM1 shedding in WT, Bace $1^{-/}$, and Bace2 $^{-/-}$glia $(n=3)$. (E) VCAM1 in medium and cell lysates of WT glia treated with vehicle or $\mathrm{CpJ}(10 \mu \mathrm{M})$ for $24 \mathrm{~h}(\mathrm{n}=3)$. (F) VCAM1 in medium and cell lysates of Bace $^{-/-}$glia treated with vehicle or CpJ $(10 \mu \mathrm{M})$ for $24 \mathrm{~h}$ $(n=3)$. (G) DNER in medium and cell lysates of Bace ${ }^{-/-}$ glia treated with vehicle or CpJ $(10 \mu \mathrm{M})$ for $24 \mathrm{~h}(\mathrm{n}=3)$. (H) Quantification of DNER shedding into conditioned medium of Bace1/-- glia treated with vehicle or CpJ for $24 \mathrm{~h}$ (paired $t$ test, $P=0.03, \mathrm{n}=3$ ). ( $\mathrm{I})$ Quantification of DNER accumulation in cell lysates of $\mathrm{Bace}^{-/-}$glia treated with vehicle or $\mathrm{Cp}$ J for $24 \mathrm{~h}$ (paired $t$ test, $P=0.3$, $\mathrm{n}=3$ ). (J) DNER shedding in WT, Bace1 ${ }^{-/-}$, and Bace2 ${ }^{-/-}$ glia $(n=3)$. (K) DNER in medium and cell lysates of WT glia treated with vehicle or $\mathrm{CpJ}(10 \mu \mathrm{M})$ for $24 \mathrm{~h}(\mathrm{n}=3)$ (L) DNER in medium and cell lysates of $\mathrm{Bace}^{-1-} \mathrm{glia}$ treated with vehicle or $\mathrm{CpJ}(10 \mu \mathrm{M})$ for $24 \mathrm{~h}(\mathrm{n}=3)$. overexpressed protein. Full-length FGFR1 overexpressed in COS-1 cells runs as a doublet around the 97-kD mobility marker (Fig 4A). When FGFR1 is co-expressed in COS-1 cells with human BACE1 or BACE2, a fragment between 51 and $64 \mathrm{kD}$ is shed into the medium, and this is inhibited by $\mathrm{CpJ}$. Thus, shedding of this fragment into the medium can be performed by both BACE2 and BACE1 in this overexpression experiment. A shed triple band running as a smear around $40 \mathrm{kD}$ is only seen upon co-expression of FGFR1 with BACE2 and may represent degradation products. In fact, these bands are not seen after CpJ treatment, indicating that it is indeed BACE2 activity that is initially responsible for their production and that likely other proteases can then further cleave the shed FGFR1. FGFR1 is likely processed by additional endogenous proteases as several additional bands appear when FGFR1 is transfected alone. It is also possible that these bands are overexpression artifacts. Thus, our transfection data confirm that FGFR1 can be processed by both BACE1 and BACE2, resulting in a shed fragment with similar mobility in SDS-PAGE and various other fragments. In the absence of good antibodies, it is impossible to explore the physiological relevance of these cleavages further.

Transfected mouse PLXDC2 (N-terminally tagged with HA and C-terminally tagged with FLAG) appeared in the lysate between 64 and $97 \mathrm{kD}$ as two bands, likely lower immature and upper glycosylated forms (Fig 4B), but it is this mature glycosylated form that is apparently processed by BACE1 or BACE2 as it disappears upon coexpression. Concomitantly, a shed fragment is observed above the 64-kD mark in the conditioned medium and this is increased with BACE1 or BACE2 co-expression. Shedding of PLXDC2 and disappearance of the mature form of PLXDC2 in the cell extracts are inhibited by $C p$ J. These overexpression data confirm that PLXDC2 can be processed by BACE2 (and BACE1) but do not yield further physiological information on the relevance of this processing event. However, this work awaits the generation of high-quality antibodies. 
A

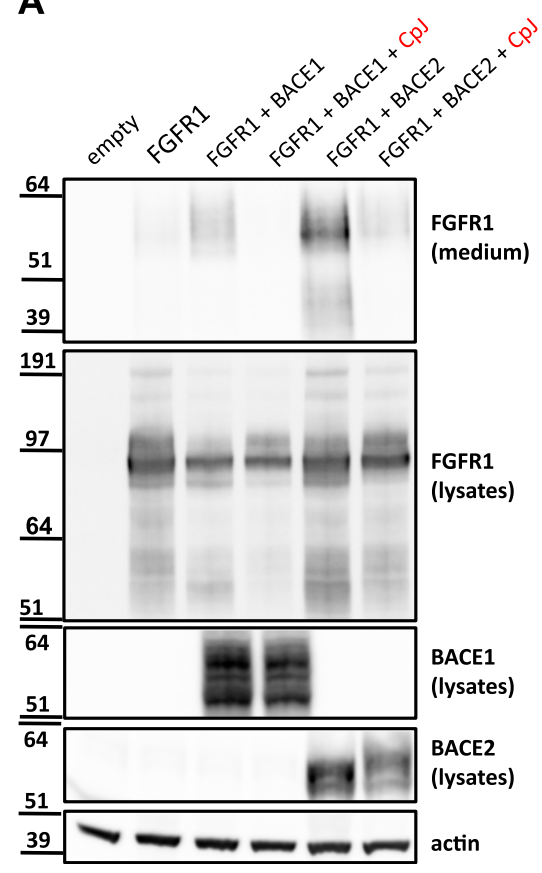

B

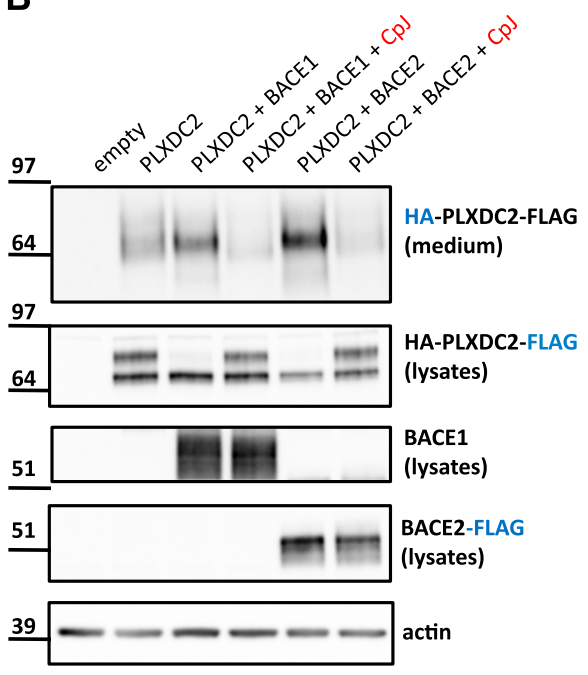

Figure 4. Validation of FGFR1 and PLXDC2 as BACE2 substrates in COS-1 overexpression system.

(A) FGFR1 in lysates and medium of COS-1 cells

overexpressing FGFR1 alone (lane 2), FGFR1 with BACE1 (lanes 3 and 4), and FGFR1 with BACE2 (lanes 5 and 6). Lanes 4 and 6 were treated with inhibitor CpJ $(10 \mu \mathrm{M})$. Lane 1 was mock-transfected with an empty vector. Representative for three experiments. (B) PLXDC2 in medium (top panel) and lysates (second panel from the top) of COS-1 cells overexpressing PLXDC2 alone (lane 2), PLXDC2 with BACE1 (lanes 3 and 4), and PLXDC2 with BACE2 (lanes 5 and 6). Lanes 4 and 6 were treated with inhibitor CpJ $(10 \mu \mathrm{M})$. Lane 1 was mock-transfected with an empty vector. Control blots for BACE1, BACE2, and actin are shown for each transfection. Representative for three experiments.

\section{Validation of Bace2 substrate candidates in vivo}

Because both VCAM1 and DNER were validated as authentic BACE2 substrates at the endogenous level in cultured glia cells, and good antibodies are available, we proceeded with their validation in CSF from WT, Bace1 ${ }^{-/-}$, Bace2 ${ }^{-/-}$, and dKO mice. The shedding of DNER and VCAM1 was compared with that of a well-known BACE1 substrate, SEZ6 (Dislich et al, 2015; Pigoni et al, 2016) (Fig 5A). As expected, the shedding of SEZ6 was significantly decreased in the CSF of Bace ${ }^{-/-}$and dKO mice but not in Bace2 ${ }^{-/-}$(Fig 5A and B), whereas no significant differences in DNER and VCAM1 were observed between genotypes (Fig $5 C$ and $D$, respectively). Similarly, no differences were observed in soluble DNER in the TBS fraction of homogenized cortices from 1-year-old male mice of different genotypes (Fig S3A and B), as well as in soluble VCAM1 in TBS fractions (Fig S3C and D). The levels of full-length proteins were found to be equal as well (Fig S3E and F). Similar results were obtained using the subdissected ventral hippocampus of 4-moold males (Fig S3G) and P16 subventricular zone (Fig S3H), brain areas where high BACE2 expression is observed. Finally, to rule out any potential compensation mechanisms occurring in vivo in $\mathrm{KO}$ animals, an acute inhibition experiment was performed in 4-mo-old $\mathrm{Bace}^{-/-}$males treated with CpJ by $4 \times$ i.p. injections at 12-h intervals. No changes in VCAM1 or DNER processing were observed (Fig S3I and J, respectively). Therefore, we conclude that under basal conditions, VCAM1 and DNER are not shed by BACE2 in the brain.

We reasoned that cultured glia, where we identified the four new BACE2 substrates, are not well representative of glia found in the adult mouse brain in basal conditions (Cahoy et al, 2008; Lange et al, 2012; LoVerso et al, 2015). As astrocytes become activated during injury, primary culture preparation from dissected brain might reflect a certain degree of inflammatory phenotype (Lange et al, 2012). Interestingly, the level of one of the BACE2 substrates identified, VCAM1, is up-regulated upon inflammatory stimulus in vitro and in vivo (van Loo et al, 2006). When we added proinflammatory agents TNF or IL-1 $\beta$ to primary glia cultures, we observed the expected up-regulation of VCAM1 and, remarkably, a strong increase in VCAM1 shedding into the medium, in particular at the 24-h time point (Fig 6A). This additional shedding is performed by BACE2, as CpJ treatment of TNF-treated Bace ${ }^{-/-}$glia blocked the increased shedding even when VCAM1 is up-regulated (Fig $6 \mathrm{~B})$. Notably, this effect of pro-inflammatory agents is specific for VCAM1 and, in contrast, leads to a down-regulation of DNER in the lysates of glia treated with TNF and IL-1B (Fig S4). Soluble DNER in the medium is already at the borderline of detection, and there are no indications of any change upon pro-inflammatory treatments (Fig S4).

Subsequently, we treated WT mice with $250 \mu \mathrm{g} / \mathrm{kg}$ TNF for $24 \mathrm{~h}$, as was previously described to induce neuroinflammation (Biesmans et al, 2015). Shed VCAM1 was increased 2.2-fold =in the CSF of mice treated with TNF (Fig 6C and D). Surprisingly, we did not observe any increase in VCAM1 in either the TBS fraction or total cell lysates of brain homogenates (Fig 6C). We finally compared the responses to TNF in WT, Bace $^{-/-}$, and Bace2 ${ }^{-/-}$mice and found that both WT and Bace ${ }^{-/-}$mice show up-regulated VCAM1 shedding into CSF upon 24-h treatment with TNF, whereas VCAM1 shedding in Bace2 ${ }^{-/-}$mice is not affected (Fig 6E and F). Thus, BACE2 is responsible for the additional shedding of VCAM1 in pro-inflammatory conditions in vitro and in vivo.

\section{Discussion}

The role of BACE2 in the pancreas and skin is generally recognized (Esterházy et al, 2011; Rochin et al, 2013; Shimshek et al, 2016), but 
A

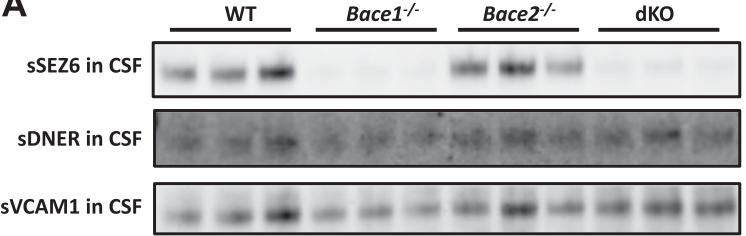

C

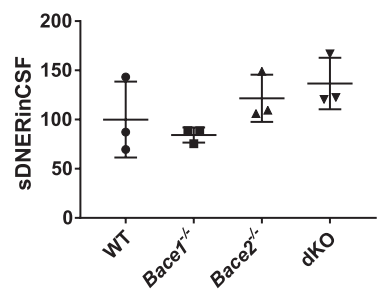

B

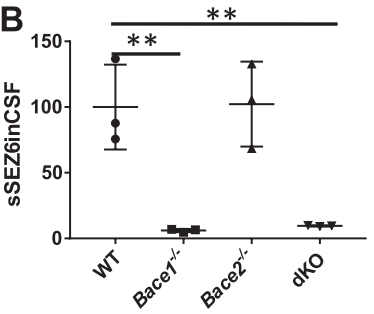

D

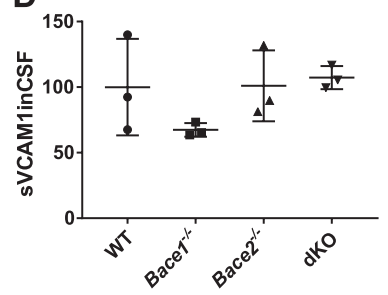

Figure 5. Absence of effects on VCAM1 and DNER in CSF of $\mathrm{Bace}^{-/-}$mice.

(A) Shed VCAM1 and DNER in triplicates of CSF of 11-moold WT, Bace ${ }^{-/-}$, Bace $2^{-/-}$, and dKO male mice, as compared with a known BACE1 substrate-SEZ6. (B) SEZ6 is significantly reduced in Bace ${ }^{-/-}$and $\mathrm{dKO}$, but not Bace $2^{-/-}$CSF compared with control WT CSF (oneway ANOVA: $P=0.006, P=0.008$, and $P=1.00$ respectively; $n=3$ ). (C) One-way ANOVA revealed no significant differences between shed DNER in Bace1 ${ }^{-/-}$ Bace $^{-/-}$, and dKO CSF, as compared with WT ( $P=1.00$, $P=1.00$, and $P=0.77$, respectively; $n=3$ ). (D) No significant differences were seen between shed VCAM1 in Bace $^{-/-}$, Bace2 ${ }^{-/-}$, dKO, and WT CSF by one-way $\operatorname{ANOVA}(P=0.76, P=1.00$, and $P=1.00$, respectively; $n=3)$. despite its relevance for AD therapy, very little is known about BACE2 expression and function in the central nervous system (CNS). Here, we show that Bace2 mRNA is present in subsets of neurons, in oligodendrocytes, and in some cells expressing the astrocyte marker Glast and lining the lateral ventricle (Fig 1). Their localization in the subventricular zone suggests that they are astrocyte-like neural stem cells (Kokovay et al, 2010), which are known to express VCAM1 (Kokovay et al, 2012). Recent single-cell sequencing shows Bace2 expression mainly in oligodendrocytes (Zhang et al, 2014), and in subsets of neurons and astrocytes (Zeisel et al, 2015), in agreement with our in situ hybridization experiments. In our study, the highest expression levels of Bace2 mRNA are seen in oligodendrocytes of the fiber tracts in young mice and in neurons of the ventral hippocampus in adult animals. In comparison, the expression pattern of Bace 1 is much wider with many neurons of the CNS, even those devoid of Bace2, displaying Bace1 mRNA, in line with previous conclusions that it is the predominant $\beta$-secretase in the brain (Cai et al, 2001; Vassar et al, 2014; Barão et al, 2016). Given the overlapping expression of Bace2 with Bace1 in neurons and oligodendrocytes, it seems logical to speculate on the redundancy of the two enzymes. Both secretases can indeed cleave similar substrates like APP (Dominguez et al, 2005; Bettegazzi et al, 2011), as well as PLXDC2 (Dislich et al, 2015) and FGFR1, which was shown in this study. However, as we will discuss in the following paragraphs, our data also point toward specific processing of VCAM1 (in vitro and in vivo) and DNER (in vitro primary cultures) exclusively by BACE2.

Having established the particular expression pattern of Bace 2 in the brain, we wondered whether there were any specific substrates for BACE2 that could further shed light on its function in the CNS. We focused our attention first on the CSF and decided to compare material from $\mathrm{dKO}\left(\right.$ Bace $^{-/-}$and $\mathrm{Bace}^{-/-}$) with single Bace ${ }^{-/-}$mice. As shown in Fig S2, the differences observed in transmembrane proteins were small and, actually, the strongest changes were up-regulated proteins without transmembrane domains, making them very unlikely BACE2 substrate candidates. Thus, in contrast to BACE1 deficiency (Dislich et al, 2015), additional depletion of BACE2 did not reveal major BACE2 substrates secreted into the CSF.
We turned to mixed primary glia cultures, where BACE2 was shown to be active (Dominguez et al, 2005). As shown in Fig 2A, we identified four novel BACE2 substrates, namely, VCAM1, FGFR1, DNER, and PLXDC2, the latter two previously reported as BACE1 substrates in other cell types and mouse CSF (Kuhn et al, 2012; Zhou et al, 2012; Stützer et al, 2013; Dislich et al, 2015). VCAM1 and DNER secretion was strongly reduced in Bace2 $^{-/-}$cells and addition of the BACE inhibitor CpJ to WT or Bace1 ${ }^{-/-}$glia inhibited their secretion, indicating that their processing is mainly performed by BACE2 in these cells (Fig 3). The evidence that FGFR1 and PLXDC2 are BACE2 substrates is more circumstantial. As no antibodies were available for FGFR1 and PLXDC2 that detect their expression at the endogenous level, we had to rely on overexpression systems to prove that BACE2, as well as BACE1, can process both (Fig 4).

VCAM1 mediates the adhesion of white blood cells to the vascular endothelium, thereby allowing immune cells to infiltrate through blood vessels (Barreiro et al, 1998). It is also involved in leukocyte homing during atherosclerosis (Gamrekelashvili \& Limbourg, 2016). In the brain, VCAM1 is found at high levels in astrocytes (Zhang et al, 2014) and is also expressed by type B neuronal stem cells at the rodent subventricular zone, where it helps maintain the rosette arrangement of these cells and regulates their lineage progression (Kokovay et al, 2012). DNER is a transmembrane protein that mediates Notch signaling through cell-cell interactions in neurons (Eiraku et al, 2002; Saito \& Takeshima, 2006). It is involved in the maturation of Bergman glia (Eiraku et al, 2005; Saito \& Takeshima, 2006). DNER has previously been identified as a BACE1 substrate in pancreatic $\beta$ cells (Stützer et al, 2013) and neurons (Kuhn et al, 2012), so it is surprising that in cultured glia cells it is not shed by BACE1, but rather exclusively by BACE2 (Fig 3) and L). According to recent RNAseq databases, Dner mRNA is expressed in oligodendrocyte precursor cells and astrocytes, as well as neurons (Zhang et al, 2014; Zeisel et al, 2015), and may have distinct functions in the different cell types.

FGFR1 is involved in signaling pathways of a variety of cells. In the mouse brain, it is expressed at high levels in astrocytes, as well as in 
A

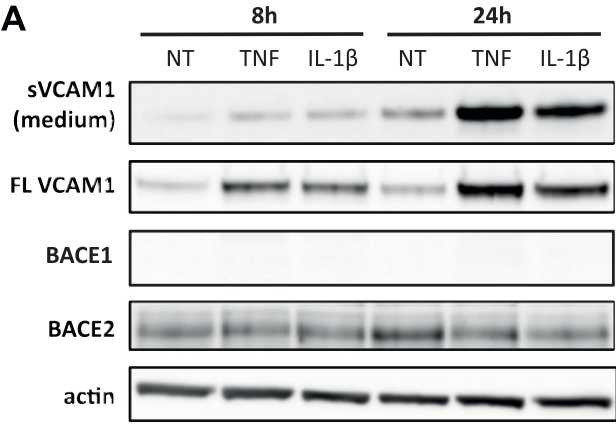

C

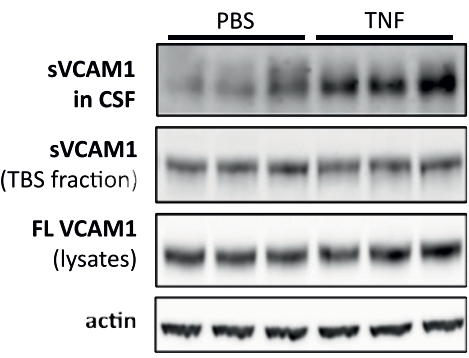

E
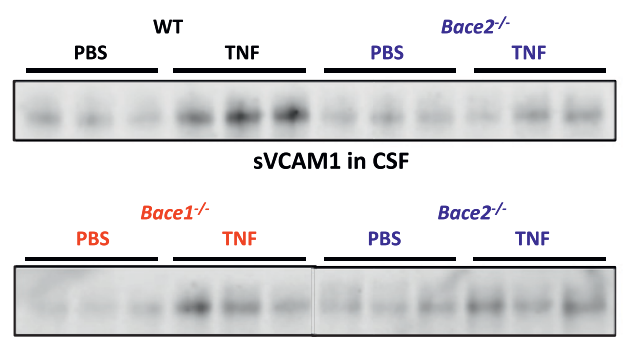

sVCAM1 in CSF
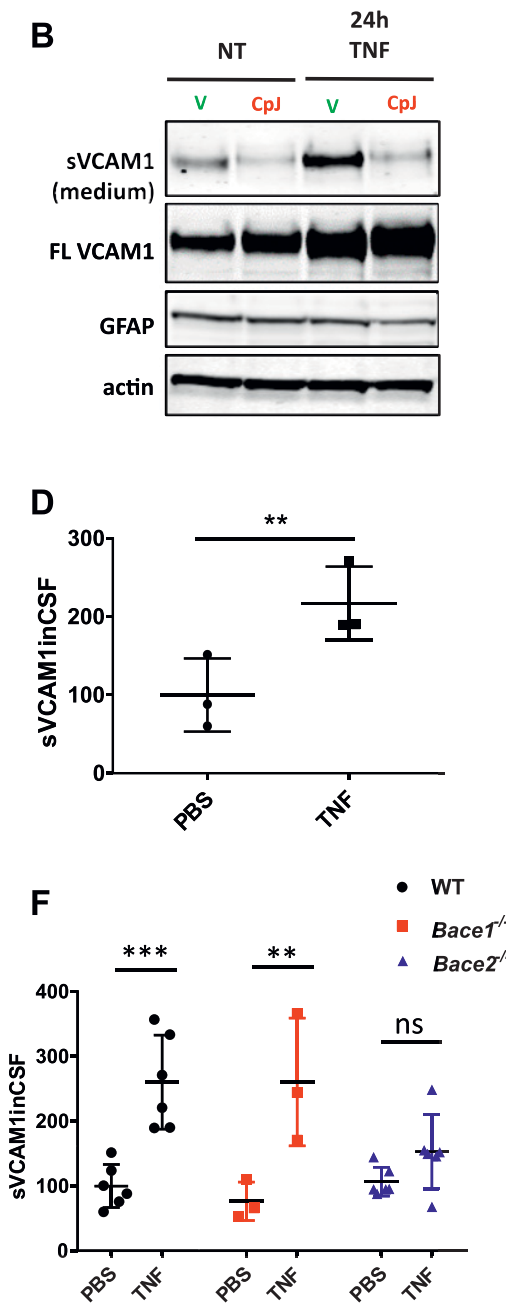

Figure 6. Validation of substrate under proinflammatory challenge in vitro and in vivo.

(A) VCAM1 in medium and lysates of primary mixed glia culture treated with murine recombinant TNF $(10 \mathrm{ng} / \mathrm{ml})$ or $\mathrm{IL}-1 \beta(10 \mathrm{ng} / \mathrm{ml})$ for $8 \mathrm{~h}$ and $24 \mathrm{~h}(\mathrm{n}=3)$ Control blots for BACE1, BACE2, and actin are shown. (B) VCAM1 in medium and lysates of primary mixed glia cells treated with murine recombinant TNF $(10 \mathrm{ng} / \mathrm{ml})$ for $24 \mathrm{~h}$, or treated with vehicle or $\mathrm{CpJ}$ inhibitor $(10 \mu \mathrm{M})$ $(n=3)$. Control blots for GFAP and actin are shown.

(c) VCAM1 in triplicates of CSF, TBS fraction, and total cell lysates of cortices from 11-mo-old WT male controls injected with PBS or treated with $250 \mu \mathrm{g} / \mathrm{kg}$ TNF. Actin is used as a loading control. (D) VCAM1 shedding into CSF is up-regulated upon TNF treatment (unpaired $t$ test, $P=0.04$; $n=3$ ), whereas no changes are observed in full-length VCAM1 or soluble VCAM1 in TBS fraction shown in (C). (E) VCAM1 in triplicates of CSF of 11-mo-old WT or Bace2 $2^{-/-}$ mice treated with saline or $250 \mu \mathrm{g} / \mathrm{kg}$ TNF (top panel) and VCAM1 in triplicates of CSF of 11-mo-old Bace ${ }^{-/-}$or Bace2 ${ }^{-/-}$ mice treated with saline or $250 \mu \mathrm{g} / \mathrm{kg}$ TNF (bottom panel) (F) Two-way ANOVA reveal significant differences in shed VCAM1 between treated and untreated WT and Bace $1^{-1-}$ mice ( $P=0.0004$ and $P=0.005$, respectively; $n=3$ ), but no significant differences in shed VCAM1 between treated and untreated Bace $^{-/-}$mice $(P=0.69)$. oligodendrocyte precursor cells (Zhang et al, 2014). PLXDC2 is a transmembrane receptor for the multifunctional pigment epitheliumderived factor important for neural growth, stem cell development, angiogenesis, and cancer cell growth, among other functions (Cheng et al, 2014). PLXDC2 is a mitogen and increases neurogenesis, resulting in thickening of the neural tube at the early stages of development (Miller et al, 2007; Miller-delaney et al, 2011). Interestingly, PLXDC2 was previously identified as a BACE1 substrate in human epithelial cell lines stably expressing BACE1 (Hemming et al, 2009), and its secretion is also affected by BACE1 deletion in mouse CSF (Dislich et al, 2015). In addition, PLXDC2 was identified as a BACE1 substrate in primary mouse neurons in two independent studies (Kuhn et al, 2012; Zhou et al, 2012).

As indicated, we did not see any major changes in shed proteins in the CSF by genetic inactivation of Bace2 on top of Bace1 (Fig S2). We revaluated the effect on the secretion of the two major BACE2 substrates identified in the primary cell culture, that is, VCAM1 and DNER, for which, coincidentally, good antibodies were also available. As shown in Figs 5 and S3, we did not see any effects on these two major BACE2 substrates in vivo, in agreement with our unbiased proteome analysis (Fig S2), suggesting that VCAM1 and DNER are not prominently shed by BACE2 at baseline conditions in vivo in the brain.

Interestingly, the most prominent substrate of BACE2, VCAM1, is known to be up-regulated during inflammation (van Loo et al, 2006). We confirmed this in our Bace ${ }^{-1-}$ mixed glia culture and found that further increase of inflammation in response to TNF or IL-1 $\beta$ additionally increased the amount of VCAM1 secreted into the media (Fig 6A). The increase was inhibited with the BACE inhibitor CPJ (Fig 6B), confirming that additional shedding was indeed BACE2dependent. Of note, the increase is likely a consequence of increased VCAM1 expression, and not necessarily caused by direct effects on BACE2 expression and/or activity (Fig 6A). We next evaluated whether we could detect BACE2 processing of VCAM1 under inflammatory conditions in vivo. We treated mice for $24 \mathrm{~h}$ with TNF, adapting a protocol previously used to induce inflammation in mouse brain (Biesmans et al, 2015). To our surprise, TNF treatment resulted in a strong up-regulation of VCAM1 in the CSF of WT and Bace $^{-/-}$animals, but did not have an effect on VCAM1 shedding in Bace2 $^{-/-}$mice. 
This intriguing result not only validates VCAM1 as an exclusive and physiologically relevant BACE2 substrate, but also implicates BACE2 in an inflammatory response pathway. Interestingly, VCAM1 is up-regulated upon injury not only in rat brains (Zhang et al, 2015), but also peripherally in AD patients (Lai et al, 2017) and increases in the CSF with age (Li et al, 2017). This suggests that similar mechanisms of inflammation-induced up-regulation of VCAM1 are relevant in humans. Further work, however, is needed to understand the exact implications of VCAM1 shedding by BACE2 under such conditions. Nonetheless, this work suggests that BACE2 function will only become apparent under specific stress conditions, explaining why until now so little effects at the phenotypic level have been described in BACE2-deficient animals.

An important lesson is to be deduced from these observations for the ongoing BACE1/2 inhibitor clinical trials. Our data predict that side effects caused by BACE2 cross-inhibition in the brain are not going to become apparent under steady-state conditions. However, BACE inhibitors are likely to be given for many years to patients and it is difficult to know what long-term effects chronic suppression of VCAM1 and other BACE2 substrates might cause. One should also take into account that AD is accompanied by CNS and maybe peripheral inflammatory alterations. It might be useful to measure VCAM1 as a marker for inflammation, as well as BACE2 activity, in the CSF and plasma of patients during the clinical trials.

\section{Materials and Methods}

\section{Animals}

The following mouse strains were used in this study: wild-type (WT) C57BL/6J@Rj (Janvier Labs), Bace1/- (Dominguez et al, 2005), C57BL/6-Bace2<tm1.2> (Bace2 ${ }^{-/-}$) (RIKEN Brain Science Institute), and double Bace1 ${ }^{-/-}$Bace2 $^{-/-} \mathrm{KO}$ (dKO) mice (Dominguez et al, 2005). The $d K O$ mouse line was produced by breeding the aforementioned Bace1 ${ }^{-/-}$mice and Bace2 $\triangle E 6$ mice, which harbor a deletion of exon 6 of Bace2 that contains the active site of the enzyme. The RIKEN Bace2 $2^{-/-}$mice used in this study lack the BACE2 protein completely. All the strains are on a $\mathrm{C} 57 \mathrm{BL} / 6$ background and were maintained on a 12/12-h light-dark cycle with ad libitum food and water. All experiments were approved by the ethics committee of the University of Leuven and performed in accordance with the Belgian and European Union regulations.

\section{Multiplex fluorescent in situ hybridization (RNAscope)}

In situ hybridization was performed using the RNAscope Fluorescent Multiplex Assay (ACD Bio) according to the manufacturer's instructions. Briefly, whole hemispheres of WT adult ( 4 mo) or WT young (P16-P20) mouse brains were frozen in molds filled with optimum cutting temperature (OCT) embedding matrix (TissueTek). Then, 14- to 16- $\mu$ m sections were prepared on Superfrost Plus slides (Thermo Fisher Scientific) using the NX70 cryostat (Thermo Fisher Scientific). The sections were fixed in 4\% PFA and dehydrated using a series of ethanol dilution steps. Protease digestion was carried out for 20 min at RT using Pretreat 4 for fresh frozen tissue provided in the RNAscope kit. Hybridization proceeded for $2 \mathrm{~h}$ at $40^{\circ} \mathrm{C}$. The following probes were used: mBace1-C2, mBace2-C1, mSyp-C3 (neuronal marker), mGlast-C3 (astrocyte marker), and mMbp-C3 (oligodendrocyte marker). Brain-specific housekeeping genes mPolr2a, mPpib, and mUbc were used as high-, medium-, and low-expressing positive control probes, respectively. Bacterial DapB probe was used as a negative control. Probe detection was performed using the four amplification reagents provided in the RNAscope kit. Images were acquired using the Leica SP8× confocal microscope and analyzed using the ImageJ software.

\section{Mouse CSF collection}

CSF was extracted from WT, Bace1 ${ }^{-/-}$, Bace2 $^{-/-}$, and dKO mice according to a previously described protocol (Liu \& Duff, 2008) with minor adjustments. A mixture of ketamine $(100 \mathrm{mg} / \mathrm{kg}$ ) and xylazine $(10 \mathrm{mg} / \mathrm{kg})$ in PBS was administered intraperitoneally to anesthetize the mice. The animal was placed on a heating pad and secured in the stereotaxic instrument with the head of the animal held at a $135^{\circ}$ angle. Hair on the head of the mouse was moved aside and held by Duratears cream and the skin of the head and neck overlying the cisterna magna was cut. Muscles and subcutaneous tissue were gently pulled aside and secured using retractors to reveal the triangular cisterna magna. The surgical field was cleaned from any blood, wiped three times with PBS, and dried if necessary. The dura was punctured with a pulled glass capillary (Sutter Instrument) attached to a syringe by tubing. The CSF was collected from the cisterna magna by applying negative pressure and transferred into a $0.5-\mathrm{ml}$ LoBind tube (Eppendorf). Following a centrifugation step at $1,500 \mathrm{~g}$ for $10 \mathrm{~min}$, clean CSF was transferred to a fresh tube and frozen at $-80^{\circ} \mathrm{C}$ until analysis.

\section{Primary glia culture and Bace inhibition experiments}

All cell culture media, PBS, HBSS, trypsin, and supplements were purchased from Invitrogen. Glia cultures were prepared from P3 mouse pups. Briefly, the cortices were cleared from meninges, cut into small pieces, digested by trypsin, and filtered through a 70- $\mu \mathrm{m}$ filter, and cells from two pups were plated on 6-cm uncoated petri dishes. Glia cultures were maintained in MEM with Earle's salt and L-glutamine, $12.5 \%$ FBS, $0.6 \%$ glucose, and pen-strep. Once confluent, each $6-\mathrm{cm}$ dish was frozen in $1 \mathrm{ml}$ freezing medium (90\% FBS and $10 \%$ DMSO) to establish a frozen stock of glia. For Bace inhibition, a previously characterized small molecule CpJ was used, which is an aminodihydrothiazine derivative inhibiting both BACE1 and BACE2 secretases (Kobayashi et al, 2007; Stützer et al, 2013).

\section{Sample preparation for LC-MS/MS analysis}

CSF samples (6 $\mathrm{Bace}^{-/-}, 5 \mathrm{dKO}$ ) were processed as previously described (Pigoni et al, 2016). Briefly, $5 \mu \mathrm{l}$ CSF was alkylated using dithiothreitol (Biomol) and iodoacetamide (Sigma-Aldrich). Proteolytic digestion was performed by using $0.1 \mu \mathrm{g}$ LysC (Promega) for $4 \mathrm{~h}$ and subsequently $0.1 \mu \mathrm{g}$ trypsin (Promega) for $16 \mathrm{~h}$ at RT in the presence of $0.1 \%(\mathrm{w} / \mathrm{v})$ sodium deoxycholate (Sigma-Aldrich). Deoxycholate was removed after acidification by centrifugation $\left(16,000 \mathrm{~g}\right.$, for $10 \mathrm{~min}$ at $\left.4^{\circ} \mathrm{C}\right)$. Peptides were purified and desalted 
using C18 stop and go extraction (Rappsilber et al, 2003). For LC-MS/ MS analysis, the peptides were dissolved in $20 \mu \mathrm{l} 0.1 \%$ formic acid (FA).

For proteomics experiments, eight vials of frozen stock Bace ${ }^{-/-}$ glia (representing 16 animals) were plated in $10 \times 10-\mathrm{cm}$ petri dishes (Fig S5A). All dishes were labeled with Click-IT ManNAz Metabolic Glycoprotein Labeling Reagent (Life Technologies). Five dishes were treated with $10 \mu \mathrm{M}$ CpJ, whereas the remaining five were treated with $20 \%$ Captisol vehicle as control, for $48 \mathrm{~h}$ in $5 \%$ FBS-containing medium. Conditioned medium was collected, filtered through a 0.45-mm PVDF filter (Millex), and concentrated using 30-kD Amicon Ultracel Centrifugal filters (Millipore). The proteomics experiment was repeated three times using independent cultures each time. The secretome protein enrichment with click sugars was used for sample preparation of conditioned cell culture medium from vehicle and $\mathrm{CpJ}$-treated glial cells as previously described (Kuhn et al, 2012). This protocol facilitates the enrichment of metabolic-labeled glycoproteins in the presence of serum proteins. Briefly, azide-labeled protein glycans were biotinylated with dibenzylcyclooctyne-PEG4-biotin (DBCO-PEG4-biotin) conjugate (Jena Bioscience) using click chemistry. The biotinylated glycoproteins were pulled down using high-capacity streptavidin agarose (Thermo Fisher Scientific). The proteins were eluted from the beads in $150 \mu \mathrm{L}$ Laemmli buffer supplemented with $8 \mathrm{M}$ urea and $3 \mathrm{mM}$ biotin at $95^{\circ} \mathrm{C}$ for $5 \mathrm{~min}$. Proteins were separated by SDS-PAGE (10\%). Coomassie staining was used to visualize the proteins. Each lane was cut into 14 fractions excluding the albumin band at $60 \mathrm{kD}$. The gel slices were subjected to protein in-gel digestion using 150 ng of trypsin (Promega) per slice (Shevchenko et al, 2007). After peptide extraction, the samples were dried using vacuum centrifugation. For LC-MS/MS analysis, the peptides were dissolved in $20 \mu \mathrm{l} 0.1 \% \mathrm{FA}$.

\section{LC-MS/MS analysis}

An Easy nLC-1000 (Thermo Fisher Scientific) equipped with a column oven (Sonation) online coupled via a nano-electrospray ion source (Thermo Fisher Scientific) to either a Q-Exactive or a Velos Pro Orbitrap Mass Spectrometer (Thermo Fisher Scientific) was used for LC-MS/MS analysis. Peptides were separated on a selfpacked C18 column (300 mm × $75 \mu \mathrm{m}$, ReproSil-Pur 120 C18-AQ, $1.9 \mu \mathrm{m}$, Dr. Maisch GmbH HPLC) using a binary gradient of water (A) and acetonitrile (B) supplemented with $0.1 \%$ FA (CSF samples: 0 min, 2\% B; 3:30 min, 5\% B; 137:30 min, 25\% B; 168:30 min, 35\% B; 182:30 min, 60\% B; $185 \mathrm{~min}, 95 \% \mathrm{~B} ; 200 \mathrm{~min}, 95 \% \mathrm{~B}$; Gel fractions of glial secretome: 0 min, 2\% B; 3:30 min, 5\% B; $48: 30$ min, 25\% B; $59: 30$ min, $35 \% \mathrm{~B} ; 64: 30 \mathrm{~min}, 60 \% \mathrm{~B})$.

CSF samples were analyzed on a Q-Exactive system using a resolution of 70,000 for full mass spectrometry spectra. The 10 most intense peptide ions per spectrum were chosen for fragmentation using higher energy collisional dissociation (AGC target: 1E+5; NCE: 25\%). A dynamic exclusion of $120 \mathrm{~s}$ was applied for fragment ion spectra acquisition.

Full mass spectrometry spectra were acquired at a resolution of 60,000 (AGC target: 3E+6). The 10 most intense peptide ions per spectrum were chosen for collision-induced dissociation within the ion trap (AGC target: 1E+4; NCE: 35\%; and activation Q: 0.25 ).
A dynamic exclusion of $90 \mathrm{~s}$ was applied for fragment ion spectra acquisition.

\section{LC-MS/MS data analysis}

Database search and LFQ were performed with the software MaxQuant (version 1.5.4.1, maxquant.org) using default settings (Cox et al, 2014). A canonical database of the reviewed reference mouse proteome (UniProt, download: June 8, 2016; 16,798 entries) was used for database search. The false discovery rate for both peptides and proteins was adjusted to $<1 \%$ using a target and decoy approach (concatenated forward/reverse database). The "match between runs" option was enabled using a time window of $1.5 \mathrm{~min}$. The LFQ intensities were calculated based on unique peptides requiring at least two ratio counts.

For relative quantification of CSF samples, LFQ intensities were log2 transformed and the average log2 ratio was calculated. At least three quantification values per group were required for statistical analysis. A Student's $t$ test was applied to check for significant changes in protein abundance.

For relative quantification of the glial secretome, the LFQ intensity ratios of $\mathrm{CpJ}$ and vehicle-treated samples were calculated separately for each experiment. At least three LFQ ratios were required for statistical analysis. All LFQ ratios were log2 transformed and a one-sample $t$ test $\left(\mu_{0}=0\right)$ was applied to check if the average log2 LFQ ratio is different from zero.

For further data analysis, protein accessions were matched against the subcellular location database of UniProt (membrane [SL-0162]; cytoplasm [SL-0086]; mitochondrion [SL-0173]; secreted [SL-0243]; nucleus [SL-0191]; cell membrane [SL-0039]; GPI-anchor [SL-9902]; single-pass type I membrane protein [SL-9905]; singlepass type II membrane protein [SL-9906]; single-pass type III membrane protein [SL-9907]; single-pass type IV membrane protein [SL-9908]; and multi-pass membrane protein [SL-9909]). In addition, all proteins were matched against the UniProt keyword database for glycoproteins [KW-0325].

\section{Validation experiments in primary glia}

Glia from Bace1 ${ }^{-/-}$and $\mathrm{Bace}^{-/-}$pups and their respective WT littermates were cultured simultaneously. For each genotype, one vial (representing two animals) was plated into a 10-cm dish (Fig S5B). At confluency, fresh serum-free medium was applied and collected after $24 \mathrm{~h}$. This experiment was repeated three times with independent cultures. In addition, WT, Bace ${ }^{-/-}$, and Bace2 ${ }^{/-}$glia were cultured in two 10-cm dishes each until confluency and treated with $\mathrm{CpJ}$ or vehicle for $24 \mathrm{~h}$ in serum-free medium (Fig S5C). Again, two animals per genotype per treatment were used and all experiments were repeated at least three times. All collected media were concentrated using the 30-kD Amicon Ultracel Centrifugal filters. Cell lysates were prepared in $50 \mathrm{mM}$ Tris- $\mathrm{HCl}, \mathrm{pH} 7.4,150 \mathrm{mM} \mathrm{NaCl}$, 2 mM EDTA, and 1\% Triton X-100 supplemented with complete protease inhibitor (Roche Applied Science). Cells were lysed for $20 \mathrm{~min}$ on ice and cleared by centrifugation at 14,000 $\mathrm{g}$ for $15 \mathrm{~min}$. Protein concentrations were measured using standard BCA assay (Pierce). 


\section{Western blotting}

$20 \mu \mathrm{g}$ of total protein was separated by SDS-PAGE on 4-12\% BisTris gels and transferred onto nitrocellulose membranes. The membranes were blocked in 5\% milk prepared in TBS-0.1\% Tween and incubated in primary antibodies overnight at $4^{\circ} \mathrm{C}$. The following primary antibodies were used: rabbit monoclonal anti-BACE1 (Cell Signaling, \#5606, clone D10E5), rabbit polyclonal anti-BACE2 produced in-house, goat polyclonal anti-VCAM1 IgG (Thermo Fisher Scientific, PA5-47029), goat polyclonal anti-DNER IgG (R\&D Systems, AF2254), mouse monoclonal anti-FGFR1 alpha antibody [M2F12] (Abcam, ab829), mouse monoclonal anti-FLAG M2 (Sigma-Aldrich, F3165), rabbit polyclonal anti-HA antibody (Clontech, 631207), and mouse monoclonal anti- $\beta$-actin (Sigma-Aldrich, A5441). The following secondary antibodies were used: goat polyclonal antimouse IgG-HRP conjugate (Biorad, 170-6516), goat polyclonal anti-rabbit IgG-HRP conjugate (Biorad, 170-6515), rabbit polyclonal anti-goat IgG-HRP conjugate (DAKO, P0449). Blots were developed using the ImageQuant LAS 4000 mini machine (GE Healthcare) and band intensities were quantified with AIDA image analyzer software (Raytest). The levels of the full-length (FL) proteins were normalized to actin levels.

\section{COS-1 cell culture and transfections}

COS- 1 cells were seeded in 10\% FBS supplemented DMEM/F-12 cell culture medium in six-well plates. All cell culture medium and supplements were purchased from Invitrogen. Transfections were performed using the TransIT-LT1 Transfection Reagent (Mirus Bio LLC) according to the manufacturer's instructions. The following constructs were used: mouse Bace1 and Bace2 in pSG5** vector as in Dominguez et al (2005), except that Bace2 construct also contained a C-terminal FLAG-tag for facilitated detection. Mouse Plxdc2 in pcDNA3.1 vector, tagged with HA-tag at the N-terminus and FLAG at the C-terminus, was previously used (Dislich et al, 2015). FGFR1 plasmid in pWZL vector (Boehm et al, 2007) was purchased from AddGene and re-cloned into the PSG5 vector by Gibson assembly. Empty pcDNA3.1 vector was used as control in all overexpression experiments. For validation of PLXDC2 and FGFR1 as BACE2 substrates, the substrate constructs were transfected either alone or together with either Bace1 or Bace2 constructs. Co-transfected wells were treated with either $10 \mu \mathrm{M}$ CpJ or vehicle; an empty vector transfection was performed as control. Three independent transfection experiments were performed for each substrate.

\section{Mouse brain tissue collection and sample prep}

Animals were euthanized using $\mathrm{CO}_{2}$ and decapitated. The brain was subdissected, snap-frozen in liquid nitrogen, and stored at $-80^{\circ} \mathrm{C}$ until further analysis. Homogenates were prepared from cortices of one hemisphere in $300 \mu \mathrm{l}$ TBS buffer (50 mM Tris-HCl, pH 7.6, and $150 \mathrm{mM} \mathrm{NaCl}$ ) supplemented with complete protease inhibitor (Roche Applied Science) using a Teflon glass homogenizer. Following centrifugation at $14,000 \mathrm{~g}$ for $15 \mathrm{~min}$, the supernatants were placed in a fresh tube and ultracentrifuged at 70,000 $\mathrm{g}$ for $30 \mathrm{~min}$ yielding the soluble TBS fractions. The remaining cell pellets were lysed in $50 \mathrm{mM}$ Tris- $\mathrm{HCl}, \mathrm{pH}$ 7.4, $150 \mathrm{mM} \mathrm{NaCl}, 2 \mathrm{mM}$ EDTA, and 1\%
Triton X-100 supplemented with complete protease inhibitor (Roche Applied Science) for $20 \mathrm{~min}$ on ice and cleared by centrifugation at $14,000 \mathrm{~g}$ for $15 \mathrm{~min}$. Protein concentrations were measured using standard BCA assay (Pierce) and the samples were analyzed by Western blotting as described above to detect the shed soluble fragments in TBS fraction and FL proteins in the total cell lysates.

\section{TNF treatment of glia cultures and mice}

Primary glia cultures were prepared from Bace1 $^{-/-}$mice as described above and two vials of frozen stock (representing four animals) were seeded into six-well plates. The cells were treated with recombinant murine TNF $(10 \mathrm{ng} / \mathrm{ml})$ or $\mathrm{IL}-1 \beta(10 \mathrm{ng} / \mathrm{ml})$ for $8 \mathrm{~h}$ or $24 \mathrm{~h}$. Three repeats of independent cultures were performed. For inhibition experiments, the cells were pretreated with $10 \mu \mathrm{M} \mathrm{CpJ} \mathrm{or}$ vehicle overnight. The next morning, the cells were simultaneously treated with $10 \mu \mathrm{M}$ CpJ or vehicle in the presence of $10 \mathrm{ng} / \mathrm{ml}$ TNF or CpJ or vehicle alone. Three repeats of independent cultures were performed. Medium was processed and total cell lysates were prepared as described above.

For in vivo experiments, WT, Bace ${ }^{-/-}$, and $\mathrm{Bace}^{-/-}$mice were treated with PBS saline or $250 \mu \mathrm{g} / \mathrm{kg}$ TNF for $24 \mathrm{~h}$; afterward CSF was extracted as described above, the mice were euthanized, and the brain was dissected and kept for analysis.

\section{Statistical analysis}

Statistical analysis for Western blot experiments was performed using the GraphPad Prism Software. For validation experiments in glia cells, immunoblot band intensity was normalized to that of a vehicle-treated sample of each independent experiment and paired $t$ test was used to determine statistical differences. Analysis of proteins in the CSF, TBS fraction, and total cell lysates of brain homogenates from different genotypes was performed by one-way ANOVA with Bonferroni post hoc test. VCAM1 measurement in the CSF of WT mice treated with PBS or TNF was analyzed using unpaired $t$ test. VCAM1 in CSF from mice of different genotypes treated with PBS or TNF was analyzed using two-way ANOVA with Tukey's multiple comparisons test. All Western blot quantifications are presented as mean \pm SD.

\section{Supplementary Information}

Supplementary Information is available at https://doi.org/10.26508/lsa. 201800026.

\section{Acknowledgements}

This work was funded by the Agency for Innovation by Science and Technology (IWT), the Stichting Alzheimer Onderzoek (SAO), the Fund for Scientific Research, Flanders, the KU Leuven, a Methusalem grant from the KU Leuven, the Flemish Government, and Vlaams Initiatief voor Netwerken voor Dementie Onderzoek (VIND, Strategic Basic Research Grant 135043), the Deutsche Forschungsgemeinschaft (FG2290), the Helmholtz-Israel program, 
the centers of excellence in neurodegeneration, and the Breuer Foundation Research award. B De Strooper is supported by the Arthur Bax and Anna Vanluffelen chair for Alzheimer's disease and "Opening the Future" of the Leuven Universiteit Fonds (LUF).

\section{Author Contributions}

I Voytyuk: Data curation, formal analysis, validation, investigation, visualization, methodology, and writing-original draft, review, and editing.

SA Mueller: Data curation, software, formal analysis, investigation, visualization, methodology, and writing-review and editing.

J Herber: Data curation, investigation, methodology, and writingreview and editing.

A Snellinx: Methodology and writing-review and editing.

D Moechars: Conceptualization, resources, supervision, funding acquisition, project administration, and writing-review and editing. $\mathrm{G}$ van Loo: Conceptualization, supervision, and writing-review and editing.

SF Lichtenthaler: Conceptualization, resources, supervision, funding acquisition, and writing-review and editing.

B De Strooper: Conceptualization, resources, supervision, funding acquisition, and writing-original draft, project administration, writing-review and editing.

\section{Conflict of Interest Statement}

B De Strooper was a consultant for Janssen Pharmaceutica and reMYND NV; I Voytyuk, SA Mueller, J Herber, A Snellinx, G van Loo, and SF Lichtenthaler declare no conflict of interest. D Moechars is a researcher of Janssen Pharmaceutica.

\section{References}

Akiyama H, Barger S, Barnum S, Bradt B, Bauer J, Cole GM, Cooper NR, Eikelenboom P, Emmerling M, Fiebich BL, et al (2000) Inflammation and Alzheimer's disease. Neurobiol Aging 21: 383-421. doi:10.1016/ s0197-4580(00)00124-X

Alcarraz-Vizán G, Castaño C, Visa M, Montane J, Servitja JM, Novials A (2017) BACE2 suppression promotes $\beta$-cell survival and function in a model of type 2 diabetes induced by human islet amyloid polypeptide overexpression. Cell Mol Life Sci 74: 2827-2838. doi:10.1007/s00018017-2505-1

Barão S, Gärtner A, Leyva-Díaz E, Demyanenko G, Munck S, Vanhoutvin T, Zhou L, Schachner M, López-Bendito G, Maness PF, et al (2015) Antagonistic effects of BACE1 and APH1B- $y$-secretase control axonal guidance by regulating growth cone collapse. Cell Rep 12: 1367-1376. doi:10.1016/ j.celrep.2015.07.059

Barão S, Moechars D, Lichtenthaler SF, De Strooper B (2016) BACE1 physiological functions may limit its use as therapeutic target for Alzheimer's disease. Trends Neurosci 39: 158-69. doi:10.1016/j. tins.2016.01.003

Barreiro O, Yáñez-mó M, Serrador JM, Montoya MC, Vicente-manzanares M, Tejedor R, Furthmayr H, Sánchez-madrid F (1998) Dynamic interaction of VCAM-1 and ICAM-1 with moesin and ezrin in a novel endothelial docking structure for adherent leukocytes. I Cell Biol 157: 1233-1245. doi:10.1083/jcb.200112126
Bennett BD, Babu-Khan S, Loeloff R, Louis JC, Curran E, Citron M, Vassar R (2000) Expression analysis of BACE2 in brain and peripheral tissues. J Biol Chem 275: 20647-20651. doi:10.1074/jbc.m002688200

Bettegazzi B, Mihailovich M, Di Cesare A, Consonni A, Macco R, Pelizzoni I, Codazzi F, Grohovaz F, Zacchetti D (2011) $\beta$-Secretase activity in rat astrocytes: Translational block of BACE1 and modulation of BACE2 expression. Eur J Neurosci 33: 236-243. doi:10.1111/j.14609568.2010.07482.x

Biesmans S, Bouwknecht JA, Ver Donck L, Langlois X, Acton PD, De Haes P, Davoodi N, Meert TF, Hellings N, Nuydens R (2015) Peripheral administration of tumor necrosis factor-alpha induces neuroinflammation and sickness but not depressive-like behavior in mice. Biomed Res Int 2015: 716920. doi:10.1155/2015/716920

Boehm JS, Zhao JJ, Yao J, Kim SY, Firestein R, Dunn IF, Sjostrom SK, Garraway LA, Weremowicz S, Richardson AL, et al (2007) Integrative genomic approaches identify IKBKE as a breast cancer oncogene. Cell 129: 1065-1079. doi:10.1016/j.cell.2007.03.052

Cahoy JD, Emery B, Kaushal A, Foo LC, Zamanian JL, Christopherson KS, Xing Y, Lubischer JL, Krieg PA, Krupenko SA, et al (2008) A transcriptome database for astrocytes, neurons, and oligodendrocytes: A new resource for understanding brain development and function. J Neurosci 28: 264-278. doi:10.1523/jneurosci.4178-07.2008

Cai H, Wang Y, McCarthy D, Wen H, Borchelt DR, Price DL, Wong PC (2001) BACE1 is the major beta-secretase for generation of Abeta peptides by neurons. Nat Neurosci 4: 233-4. doi:10.1038/85064

Cebers G, Alexander RC, Haeberlein SB, Han D, Goldwater R, Ereshefsky L, Olsson T, Ye N, Rosen L, Russell M, et al (2016a) AZD3293: Pharmacokinetic and pharmacodynamic effects in healthy subjects and patients with Alzheimer's disease. J Alzheimers Dis 55: 1039-1053. doi:10.3233/jad-160701

Cebers G, Lejeune T, Attalla B, Soderberg M, Alexander SRC, Haeberlein SB, Kugler AR, Ingersoll EW, Platz S, Scott CW (2016b) Reversible and species-specific depigmentation effects of AZD3293, a BACE inhibitor for the treatment of Alzheimer's disease, are related to BACE2 inhibition and confined to epidermis and hair. J Prev Alzheimers Dis 3: 202-218. doi:10.14283/jpad.2016.119

Cheng G, Zhong M, Kawaguchi R, Kassai M (2014) Identification of PLXDC1 and PLXDC2 as the transmembrane receptors for the multifunctional factor PEDF. Elife 3:e05401. doi:10.7554/eLife.05401

Cole SL, Vassar R (2007) The basic biology of BACE1 : A key therapeutic target for Alzheimer's disease. Curr Genomics 8: 509-530. doi:10.2174/ 138920207783769512

Cox J, Hein MY, Luber CA, Paron I, Nagaraj N, Mann M (2014) Accurate proteome-wide label-free quantification by delayed normalization and maximal peptide ratio extraction, termed MaxLFQ. Mol Cell Proteomics 13: 2513-2526. doi:10.1074/mcp.m113.031591

De Strooper B (2014) Lessons from a failed y-secretase Alzheimer trial. Cell 159: 721-726. doi:10.1016/j.cell.2014.10.016

De Strooper B, Saftig P, Craessaerts K, Vanderstichele H, Guhde G, Annaert W, Von Figura K, Van Leuven F (1998) Deficiency of presenilin-1 inhibits the normal cleavage of amyloid precursor protein. Nature 391: 387-90. doi:10.1038/34910

Deckx S, Heymans S, Papageorgiou AP (2016) The diverse functions of osteoglycin: A deceitful dwarf, or a master regulator of disease. FASEB J 30: 2651-2661. doi:10.1096/fj.201500096r

Dislich B, Wohlrab F, Bachhuber T, Müller SA, Kuhn P-H, Hogl S, MeyerLuehmann M, Lichtenthaler SF (2015) Label-free quantitative proteomics of mouse cerebrospinal fluid detects $\beta$-site APP cleaving enzyme (BACE1) protease substrates in vivo. Mol Cell Proteomics 14: 2550-2563. doi:10.1074/mcp.m114.041533

Dominguez D, Tournoy J, Hartmann D, Huth T, Cryns K, Deforce S, Serneels L, Camacho IE, Marjaux E, Craessaerts K, et al (2005) Phenotypic and 
biochemical analyses of BACE1- and BACE2-deficient mice. J Biol Chem 280: 30797-30806. doi:10.1074/jbc.m505249200

Doody RS, Raman R, Farlow M, Iwatsubo T, Vellas B, Joffe S, Kieburtz K, He F, Sun X, Thomas RG, et al (2013) A phase 3 trial of semagacestat for treatment of Alzheimer's disease. N Engl J Med 369: 341-50. doi:10.1056/nejmoa1210951

Eiraku M, Hirata Y, Takeshima H, Hirano T, Kengaku M (2002) Delta/notch-like epidermal growth factor (EGF)-related receptor, a novel EGF-like repeat-containing protein targeted to dendrites of developing and adult central nervous system neurons. J Biol Chem 277: 25400-25407. doi:10.1074/jbc.M110793200

Eiraku M, Tohgo A, Ono K, Kaneko M, Fujishima K, Hirano T, Kengaku M (2005) DNER acts as a neuron-specific Notch ligand during Bergmann glial development. Nat Neurosci 8: 873-880. doi:10.1038/nn1492

Esterházy D, Stützer I, Wang H, Rechsteiner MP, Beauchamp J, Döbeli H, Hilpert $H$, Matile $H$, Prummer M, Schmidt A, et al (2011) Bace2 is a $\beta$ cellenriched protease that regulates pancreatic $\beta$ cell function and mass. Cell Metab 14: 365-377. doi:10.1016/j.cmet.2011.06.018

Farzan M, Schnitzler CE, Vasilieva N, Leung D, Choe H (2000) BACE2, a $\beta$-secretase homolog, cleaves at the $\beta$ site and within the amyloid- $\beta$ region of the amyloid- $\beta$ precursor protein. PNAS 97: 9712-9717. doi:10.1073/pnas.160115697

Fleck D, van Bebber F, Colombo A, Galante C, Schwenk BM, Rabe L, Hampel H, Novak B, Kremmer E, Tahirovic S, et al (2013) Dual cleavage of neuregulin 1 type III by BACE1 and ADAM17 liberates its EGF-like domain and allows paracrine signaling. J Neurosci 33: 7856-69. doi:10.1523/jneurosci.3372-12.2013

Gamrekelashvili J, Limbourg FP (2016) Rules of attraction: Endothelial Notch signalling controls leucocyte homing in atherosclerosis via Vcam1. Cardiovasc Res 112: 527-529. doi:10.1093/cvr/cvw207

Hardy J, Selkoe DJ (2002) The amyloid hypothesis of Alzheimer's disease: Progress and problems on the road to therapeutics. Science 297: 353-356. doi:10.1126/science.1072994

Hasan M, Seo JE, Rahaman KA, Min H, Kim KH, Park JH, Sung C, Son J, Kang MJ, Jung $\mathrm{BH}$, et al (2017) Novel genes in brain tissues of EAE-induced normal and obese mice: Upregulation of metal ion-binding protein genes in obese-EAE mice. Neuroscience 343: 322-336. doi:10.1016/j. neuroscience.2016.12.002

Hemming ML, Elias JE, Gygi SP, Selkoe DJ (2009) Identification of betasecretase (BACE1) substrates using quantitative proteomics. PLoS One 4: e8477. doi:10.1371/journal.pone.0008477

Hitt B, Riordan SM, Kukreja L, Eimer WA, Rajapaksha TW, Vassar R (2012) $\beta$-Site amyloid precursor protein (APP)-cleaving enzyme 1 (BACE1)-deficient mice exhibit a close homolog of L1 (CHL1) loss-of-function phenotype involving axon guidance defects. J Biol Chem 287: 38408-38425. doi:10.1074/jbc.m112.415505

Hu X, Hicks CW, He W, Wong P, Macklin WB, Trapp BD, Yan R (2006) Bace1 modulates myelination in the central and peripheral nervous system. Nat Neurosci 9: 1520-5. doi:10.1038/nn1797

Hu X, Fan Q, Hou H, Yan R (2016) Neurological dysfunctions associated with altered BACE1-dependent Neuregulin-1 signaling. J Neurochem 136: 234-249. doi:10.1111/jnc.13395

Kennedy ME, Stamford AW, Chen X, Cox K, Cumming JN, Dockendorf MF, Egan M, Ereshefsky L, Hodgson RA, Hyde LA, et al (2016) The BACE1 inhibitor verubecestat (MK-8931) reduces CNS $\beta$-amyloid in animal models and in Alzheimer's disease patients. Sci Transl Med 8: 363ra150. doi:10.1126/scitranslmed.aad9704

Kobayashi, NJ, Ueda, K, Itoh, N, Suzuki, S, Sakaguchi, G, Kato, A, Yukimasa, A, Hori, A, Koriyama, Y, Haraguchi, H, et al (2007) Aminodihydrothiazine derivative. International Patent Application, WO2007/049532, filed October 23, 2006, and issued May 3, 2007, Japan.

Kokovay E, Goderie S, Wang Y, Lotz S, Lin G, Sun Y, Roysam B, Shen Q, Temple S (2010) Adult svz lineage cells home to and leave the vascular niche via differential responses to SDF1/CXCR4 signaling. Cell Stem Cell 7: 163-173. doi:10.1016/j.stem.2010.05.019

Kokovay E, Wang Y, Kusek G, Wurster R, Lederman P, Lowry N, Shen Q, Temple S (2012) VCAM1 is essential to maintain the structure of the SVZ niche and acts as an environmental sensor to regulate SVZ lineage progression. Cell Stem Cell 11: 220-230. doi:10.1016/j.stem.2012.06.016

Kuhn P-H, Koroniak K, Hogl S, Colombo A, Zeitschel U, Willem M, Volbracht C Schepers U, Imhof A, Hoffmeister A, et al (2012) Secretome protein enrichment identifies physiological BACE1 protease substrates in neurons. EMBO / 31: 3157-3168. doi:10.1038/emboj.2012.173

Lai KSP, Liu CS, Rau A, Lanctôt KL, Köhler CA, Pakosh M, Carvalho AF, Herrmann N (2017) Peripheral inflammatory markers in Alzheimer's disease: A systematic review and meta-analysis of 175 studies. J Neurol Neurosurg Psychiatry 88: 876-882. doi:10.1136/jnnp-2017-316201

Lange SC, Bak LK, Waagepetersen HS, Schousboe A, Norenberg MD (2012) Primary cultures of astrocytes: Their value in understanding astrocytes in health and disease. Neurochem Res 37: 2569-2588. doi:10.1007/s11064-012-0868-0

Li G, Shofer JB, Petrie EC, Yu C, Wilkinson CW, Figlewicz DP, Shutes-david A, Zhang J, Montine TJ, Raskind MA, et al (2017) Cerebrospinal fluid biomarkers for Alzheimer's and vascular disease vary by age, gender, and APOE genotype in cognitively normal adults. 9: 48. doi:10.1186/ s13195-017-0271-9

Liu L, Duff K (2008) A technique for serial collection of cerebrospinal fluid from the cisterna magna in mouse. J Vis Exp 960. doi:10.3791/960

LoVerso PR, Wachter CM, Cui F (2015) Cross-species transcriptomic comparison of in vitro and in vivo neural cells. Bioinform Biol Insights 9: 153-164. doi:10.4137/bbi.s33124

Miller SFC, Summerhurst K, Rünker AE, Kerjan G, Friedel RH, Chédotal A, Murphy P, Mitchell KJ (2007) Expression of Plxdc2/TEM7R in the developing nervous system of the mouse $7:$ 635-644. doi:10.1016/j. modgep.2006.12.002

Miller-Delaney SFC, Lieberam I, Murphy P, Mitchell KJ (2011) Plxdc2 is a mitogen for neural progenitors. PLoS One 6: e14565. doi:10.1371/ journal.pone.0014565

Munro KM, Nash A, Pigoni M, Lichtenthaler SF, Gunnersen JM (2016) Functions of the Alzheimer's disease protease BACE1 at the synapse in the central nervous system. J Mol Neurosci 60: 305-315. doi:10.1007/ s12031-016-0800-1

Neumann U, Rueeger $H$, Machauer R, Veenstra SJ, Lueoend RM, TintelnotBlomley M, Laue G, Beltz K, Vogg B, Schmid P, et al (2015) A novel BACE inhibitor NB-360 shows a superior pharmacological profile and robust reduction of amyloid- $\beta$ and neuroinflammation in APP transgenic mice. Mol Neurodegener 10: 44. doi:10.1186/s13024-0150033-8

Pigoni M, Wanngren J, Kuhn P-H, Munro KM, Gunnersen JM, Takeshima H, Feederle R, Voytyuk I, De Strooper B, Levasseur MD, et al (2016) Seizure protein 6 and its homolog seizure 6 -like protein are physiological substrates of BACE1 in neurons. Mol Neurodegener 11: 67. doi:10.1186/ s13024-016-0134-z

Rappsilber J, Ishihama Y, Mann M (2003) Stop and go extraction tips for matrix-assisted laser desorption/ionization, nanoelectrospray, and LC/MS sample pretreatment in proteomics. Anal Chem 75: 663-670. doi:10.1021/ac026117i

Rochin L, Hurbain I, Serneels L, Fort C, Watt B, Leblanc P, Marks MS, De Strooper B, Raposo G, van Niel G (2013) BACE2 processes PMEL to form the melanosome amyloid matrix in pigment cells. Proc Natl Acad Sci U S A 110: 10658-63. doi:10.1073/pnas.1220748110

Rulifson IC, Cao P, Miao L, Kopecky D, Huang L, White RD, Samayoa K, Gardner J, Wu X, Chen K, et al (2016) Identification of human islet amyloid polypeptide as a BACE2 substrate. PLoS One 11: e0147254. doi:10.1371/ journal.pone.0147254 
Saito S, Takeshima H (2006) DNER as key molecule for cerebellar maturation. Cerebellum 11: 227-231. doi:10.1080/14734220600632564

Sastre M, Klockgether T, Heneka MT (2006) Contribution of inflammatory processes to Alzheimer's disease: Molecular mechanisms. Int I Dev Neurosci 24: 167-176. doi:10.1016/j.ijdevneu.2005.11.014

Shevchenko A, Tomas H, Havlis J, Olsen JV, Mann M (2007) In-gel digestion for mass spectrometric characterization of proteins and proteomes. Nat Protoc 1: 2856-2860. doi:10.1038/nprot.2006.468

Shimshek DR, Jacobson LH, Kolly C, Zamurovic N, Balavenkatraman KK Morawiec L, Kreutzer R, Schelle J, Jucker M, Bertschi B, et al (2016) Pharmacological BACE1 and BACE2 inhibition induces hair depigmentation by inhibiting PMEL17 processing in mice. Sci Rep 6: 21917. doi:10.1038/srep21917

Silverman GA, Bird PI, Carrell RW, Church FC, Coughlin PB, Gettins PGW, Irving JA, Lomas DA, Luke CJ, Moyer RW, et al (2001) The serpins are an expanding superfamily of structurally similar but functionally diverse proteins. J Biol Chem 276: 33293-33296. doi:10.1074/jbc.r100016200

Stützer I, Selevsek N, Esterházy D, Schmidt A, Aebersold R, Stoffel M (2013) Systematic proteomic analysis identifies $\beta$-site amyloid precursor protein cleaving enzyme 2 and 1 (BACE2 and BACE1) substrates in pancreatic $\beta$-cells. J Biol Chem 288: 10536-10547. doi:10.1074/jbc. m112.444703

Szaruga M, Munteanu B, Lismont S, Veugelen S, Horré K, Mercken M, Saido TC, Ryan NS, De Vos T, Savvides SN, et al (2017) Alzheimer's-causing mutations shift $A \beta$ length by destabilizing $y$-secretase- $a \beta n$ interactions. Cell 170: 443-456.e14. doi:10.1016/j.cell.2017.07.004

Taupenot L, Harper KL, O'Connor DT (2003) The chromogranin-secretogranin family. N Engl J Med 348: 1134-1149. doi:10.1056/nejmra021405

van Loo G, de Lorenzi R, Schmidt H, Huth M, Mildner A, Schmidt-Supprian M, Lassmann H, Prinz MR, Pasparakis M (2006) Inhibition of transcription factor NF-kappaB in the central nervous system ameliorates autoimmune encephalomyelitis in mice. Nat Immunol 7: 954-961. doi:10.1038/ni1372

Van Bebber F, Hruscha A, Willem M, Schmid B, Haass C (2013) Loss of Bace2 in zebrafish affects melanocyte migration and is distinct from Bace1 knock out phenotypes. J Neurochem 127: 471-481. doi:10.1111/jnc.12198

Vassar R, Bennett BD, Babu-khan S, Kahn S, Mendiaz EA, Denis P, Teplow DB, Ross S, Amarante P, Loeloff R, et al (1999) Beta-secretase cleavage of Alzheimer's amyloid precursor protein by the transmembrane aspartic protease BACE. Science 286: 735-742. doi:10.1126/ science.286.5440.735

Vassar R, Kuhn P-H, Haass C, Kennedy ME, Rajendran L, Wong PC, Lichtenthaler SF (2014) Function, therapeutic potential and cell biology of BACE proteases: Current status and future prospects. J Neurochem 130: 4-28. doi:10.1111/jnc.12715
Voytyuk I, De Strooper B, Chavez-Gutierrez L (2018) Modulation of $\gamma$ - and $\beta$-secretases as early prevention against Alzheimer's disease. Biol Psychiatry 83: 320-327. doi:10.1016/j.biopsych.2017.08.001

Wang W, Tan M, Yu J, Tan L (2015) Role of pro-inflammatory cytokines released from microglia in Alzheimer's disease. Ann Transl Med 3: 1-15

Wiera G, Mozrzymas JW (2015) Extracellular proteolysis in structural and functional plasticity of mossy fiber synapses in hippocampus. Front Cell Neurosci 9: 1-21. doi:10.3389/fncel.2015.00427

Willem M, Garratt AN, Novak B, Citron M, Kaufmann S, Rittger A, De Strooper B, Saftig P, Birchmeier C, Haass C (2006) Control of peripheral nerve myelination by the $\beta$-secretase BACE1. Science 314: 664-666.

Wright AG, Demyanenko GP, Powell A, Schachner M, Enriquez-Barreto L, Tran TS, Polleux F, Maness PF (2007) Close homolog of L1 and neuropilin 1 mediate guidance of thalamocortical axons at the ventral telencephalon. J Neurosci 27: 13667-13679. doi:10.1523/jneurosci.288807.2007

Yan R, Vassar R (2014) Targeting the $\beta$ secretase BACE1 for Alzheimer's disease therapy. Lancet Neurol 13: 319-29. doi:10.1016/s1474-4422(13) $70276-x$

Zeisel A, Munoz-Manchado AB, Codeluppi S, Lonnerberg P, La Manno G, Jureus A, Marques S, Munguba H, He L, Betsholtz C, et al (2015) Brain structure. Cell types in the mouse cortex and hippocampus revealed by single-cell RNA-seq. Science 347: 1138-1142. doi:10.1126/science. aaa1934

Zhang D, Yuan D, Shen J, Yan Y, Gong C, Gu J, Xue H, Qian Y, Zhang W, He X, et al (2015) Up-regulation of VCAM1 relates to neuronal apoptosis after intracerebral hemorrhage in adult rats. Neurochem Res 40: 1042-1052. doi:10.1007/s11064-015-1561-x

Zhang Y, Chen K, Sloan Sa, Bennett ML, Scholze AR, Keeffe SO, Phatnani HP, Guarnieri XP, Caneda C, Ruderisch N, et al (2014) An RNA-sequencing transcriptome and splicing database of glia, neurons, and vascular cells of the cerebral cortex. 34: 1-19. doi:10.1523/jneurosci.186014.2014

Zhou L, Barão S, Laga M, Bockstael K, Borgers M, Gijsen H, Annaert W, Moechars D, Mercken M, Gevaer K, et al (2012) The neural cell adhesion molecules L1 and CHL1 are cleaved by BACE1 protease in vivo. J Biol Chem 287: 25927-25940. doi:10.1074/jbc.m112.377465

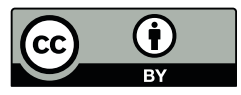

License: This article is available under a Creative Commons License (Attribution 4.0 International, as described at https://creativecommons.org/ licenses/by/4.0/). 